\title{
Emergence and Refinement of Clustered Horizontal Connections in Cat Striate Cortex
}

\author{
Edward M. Callaway and Lawrence C. Katz \\ Laboratory of Neurobiology, The Rockefeller University, New York, New York 10021
}

Pyramidal cells in layer $2 / 3$ of adult cat striate cortex have long, intrinsic horizontal axon collaterals within both layer $2 / 3$ and layer 5 . These collaterais form periodic "clusters" of finer axon branches that link columns of similar orientation selectivity. We have investigated the sequence of events and possible mechanisms underlying the development of these clustered intrinsic horizontal connections using a combination of neuronal tracers and intracellular staining. Small injections of fluorescent latex microspheres made during the first postnatal week (at P4-6), when examined in tangential sections, produced an even, unclustered distribution of retrogradely labeled cells up to $2 \mathrm{~mm}$ from the injection site. At $\mathbf{P 8}$, retrograde labeling extended over a larger area and clustering was discernible, primarily among the most distant labeled cells. At both P6 and P8, labeling was similar in layers $2 / 3$ and 5 , indicating that the transition from clustered to unclustered connections occurred simultaneously for cells in superficial and deep laminae. By the end of the second postnatal week (P12-15), retrogradely labeled cells were far more clustered both within and beyond the extent of P6 label; the density of labeled cells was high throughout the labeled region, but much higher within clusters. The periodicity of these nascent clusters was similar to that in the adult. Despite obvious clustering, the pattern of retrograde label observed following injections at 2-3 weeks (P12-21) differed markedly from the adult, in that the regions between clusters contained many labeled cells. Over the next 3 weeks, the connections were refined, so that by the sixth postnatal week (P36-38), regions between clusters contained very few retrogradely labeled cells and the overall pattern of retrograde label was indistinguishable from that in adults. Despite differences in postmigratory ages of neurons from the superficial and deep laminae, clustering of retrogradely labeled cells from these 2 populations was similar at all ages.

Experiments in which 2-3 weeks elapsed between the time microsphere injections were made and animals were killed demonstrated that neither the initial formation of crude clusters nor their refinement was due to cell death. Instead, cluster refinement resulted from specific process elimina-

\footnotetext{
Received Sept. 1, 1989; revised Oct. 25, 1989; accepted Oct. 26, 1989

We thank Drs. David Sretavan and Torsten Wiesel for their comments on the manuscript, and Peter Peirce for expert photographic assistance. Supported by EY06 128 (E.M.C.) and EY07960 (L.C.K.). L.C.K. is a Lucille P. Markey Scholar, and this work was supported in part by a grant from the L. P. Markey Charitable Trust

Correspondence should be addressed to Edward M. Callaway, Laboratory of Neurobiology, Box 138, The Rockefeller University, 1230 York Avenue, New York, NY 10021

Copyright (c) 1990 Society for Neuroscience $0270-6474 / 90 / 041134-20 \$ 02.00 / 0$
}

tion. When a red microsphere injection at $P 15$ was foilowed by a green microsphere injection at exactly the same location on P29, the earlier injection resulted in crude clustering, as expected. Virtually all of the cells double-labeled by the later injection were within the densest clusters of label from the early injection.

Analysis of neurons intracellularly stained in tangential brain slices during the first 3 postnatal weeks revealed a steady increase in the number of long, unbranched horizontal axon collaterals extending from the efferent axons of pyramidal cells in superficial cortical layers; clustering of axonal arbors was not apparent. During the fourth postnatal week, the number of collaterals extending from the regions of cell bodies decreased and axonal arbors took on a more clustered appearance, apparently reflecting the specific elimination of inappropriately projecting collaterals. The final phase in the maturation of axonal arbors was extensive and specific elaboration of fine collateral branches within appropriate target regions, which by 7 weeks after birth gave the arbors their characteristic adult appearance.

Visual cortical neurons form extensive horizontal connections that are much longer than the distance between the classic cortical columns (Gilbert and Wiesel, 1979, 1983; Rockland and Lund, 1983; Martin and Whitteridge, 1984; Rockland, 1985). A clear relation between horizontal connections and columnar organization has been demonstrated in the primary visual cortex of both cats and monkeys. In the monkey, for example, intrinsic horizontal axons connect cytochrome oxidase-rich blobs to neighboring blobs, and nonblobs to other nonblob regions (Livingstone and Hubel, 1984). In cat striate cortex, pyramidal cells in layer $2 / 3$ have long horizontal axon collaterals in layers $2 / 3$ and 5 , with finer collateral branches distributed in repeating clusters (Gilbert and Wiesel, 1979, 1983; Martin and Whitteridge, 1984) that interconnect columns with similar orientation preference (Gilbert and Wiesel, 1989). Thus, long-distance horizontal connections appear to mediate interactions between distant portions of the visual field without disrupting the columnar nature of the cortical structure

How such precise horizontal connections are formed is poorly understood. Most studies of the development of cortical connectivity have focused on pathways between brain areas; few have investigated how local circuits emerge. In many systems where visual cortical neurons connect to distant targets, an early period of exuberant axonal outgrowth is followed by a period of selective axon withdrawal (Innocenti and Caminiti, 1980; O'Leary et al., 1981; Price and Blakemore, 1985a, b; Stanfield and O'Leary, 1985; O'Leary and Terashima, 1988). On the other hand, interlaminar connections of layer $2 / 3$ pyramidal cells de- 
velop in a conservative manner; the original outgrowth of axons is specific to the appropriate layers (Katz and Wiesel, 1987). We therefore investigated whether clustered intrinsic horizontal connections within a cortical layer develop conservatively, growing specifically to correct targets, or by exuberant growth followed by selective process elimination or cell death. Furthermore, since there is a considerable difference in the ages at which cells in layer $2 / 3$ and layer 5 reach their final position in the cortex (Shatz and Luskin, 1986), we investigated whether the emergence of clustered connections occurs simultaneously or sequentially for cells in these laminae.

\section{Materials and Methods}

Summary. We investigated the development of intrinsic horizontal circuitry in a total of 24 kittens at 4-54 d postnatally (P4-54) and 2 adult cats. Rhodamine and/or fluorescein conjugated latex microspheres ("red" or "green" beads; Katz et al., 1984; Katz and Iarovici, 1989) were injected into the striate cortex of both adult cats and 18 kittens. The numbers of successful injections and kittens injected grouped according to age are indicated in Table 1 . In addition, one paraformaldehydefixed hemisphere from each of 6 bead-injected animals was used for DiI injection (also indicated in Table 1). Of the 6 kittens not injected with microspheres, 2 were injected with DiI only; the remaining 4 were used to prepare in vitro slices of area 17 for intracellular Lucifer yellow (LY) staining. For LY experiments, one animal each was studied at P16 ( 28 cells), P23 ( 9 cells), P30 ( 9 cells), and P43 ( 3 cells).

\section{Neuronal pathway tracing}

Injection of fluorescent latex microspheres. Cats were anesthetized with halothane $\left(1-3 \%\right.$ in $\left.\mathrm{O}_{2}\right)$ and secured in a stereotaxic holder. Under sterile conditions, injections of the retrograde neuronal tracers, red and/or grecn beads, were placed in area 17. Up to 4 injections ( 2 per hemisphere) were placed in each animal. For each injection a separate craniotomy with a diameter of $1.5-2 \mathrm{~mm}$ was made directly over the region to be injected. A small hole was made in the dura through which a microsphere-filled, glass micropipette (tip diameter about $25 \mu \mathrm{m}$ ) attached to a micromanipulator was lowered about $600-850 \mu \mathrm{m}$ into the cortex perpendicular to the cortical laminae. After positioning, $300-400 \mathrm{nl}$ of microspheres were pressure injected into the cortex. Since the microspheres tend to reflux up along the edges of the pipette, from its tip to the cortical surface, this resulted in a fine column of beads distributed throughout the cortical laminae. Because microspheres diffuse very little from the injection site, injection sites were small, typically $100-400 \mu \mathrm{m}$ in diameter (see Fig. 1).

All injections were placed in area 17 in an AP position between ear bar zero and the bregma suture. The most anterior injections were made within $1 \mathrm{~mm}$ of the midline and the more posterior injections within $3 \mathrm{~mm}$. The positions of these injections within area 17 were later confirmed based on visual inspection of the injection site in the intact cortex following perfusion of the animal, and the location and sizes of retrogradely labeled cells in the lateral geniculate nucleus (LGN). The injections were positioned such that contamination by transport via callosal axons from the opposite hemisphere or via horizontal axons within the same hemisphere from an injection of the same color microspheres would not occur.

In some experiments, 2 injections ( 1 red and 1 green) were made at the same location on different days (see Table 1). In these experiments the first injection was made as described above. The second injection was made through the original craniotomy, which had not yet closed. It was sometimes necessary to enlarge the craniotomy by up to $1 \mathrm{~mm}$ in diameter to find the original injection site. The position of the original injection could be identified by first locating microspheres that had remained on the dura, then making a small hole in the dura through which the injection site in the cortex could be visualized with a standard dissecting microscope. The second injection was made as close as possible to the first and in the same manner as described above.

Analysis of microsphere-injected animals. Animals survived at least $24 \mathrm{hr}$ following injections of fluorescent microspheres (as indicated in Table 1). This survival time results in extensive label within the LGN (see below), confirming that the survival time was adequate to allow transport even much further than the extent of intrinsic horizontal connections within area 17.
Table 1. Cortical hemispheres used for tracer injections arranged according to postnatal age at time of injection and time of perfusion

\begin{tabular}{|c|c|c|c|}
\hline Hemisphere & Injection age (d) & Perfusion age (d) & $\begin{array}{l}\text { Injection } \\
\text { type }\end{array}$ \\
\hline $\mathrm{K} 42 \mathrm{R}$ & 4 & 5 & Red \\
\hline K40R & 5 & 6 & Green \\
\hline $\mathrm{K} 40 \mathrm{~L}$ & 6 & 6 & DiI \\
\hline K43L & 6 & 7 & Green \\
\hline K45R & 8 & 9 & Red \\
\hline $\mathrm{K} 31 \mathrm{~L}$ & 12 & 13 & Red \\
\hline K31R & 12 & 13 & Green \\
\hline K32L & 14 & 15 & Red \\
\hline K55R & 14 & 16 & Red \\
\hline K49L & 15 & 15 & DiI \\
\hline K48L & 15 & 15 & DiI \\
\hline $\mathrm{K} 28 \mathrm{R}$ & 17 & 18 & Red \\
\hline K33R & 19 & 20 & Red \\
\hline K29R & 21 & 22 & Green \\
\hline $\mathrm{K} 52 \mathrm{~L}$ & 31 & 31 & DiI \\
\hline K53R & 36 & 38 & Red \\
\hline K47R & 37 & 39 & Red \\
\hline K44L & 38 & 39 & Green \\
\hline $\mathrm{K} 44 \mathrm{R}$ & 38 & 39 & Green \\
\hline K53L & 38 & 38 & Dil \\
\hline K47L & 39 & 39 & DiI \\
\hline K39R & 52 & 54 & Red \\
\hline K39L & 54 & 54 & DiI \\
\hline KA2L & Adult & Adult & Green \\
\hline KA3L & Adult & Adult & Red \\
\hline KA2R & Adult & Adult & DiI \\
\hline \multicolumn{4}{|c|}{ Delayed perfusion } \\
\hline $\mathrm{K} 57 \mathrm{~L}$ & 6 & 16 & Green \\
\hline $\mathrm{K} 58 \mathrm{R}$ & 6 & 16 & Red \\
\hline K56R & 14 & 40 & Green \\
\hline K53R & 15 & 38 & Red \\
\hline K53R & 15 & 38 & Green \\
\hline K47R & 15 & 39 & Red \\
\hline \multicolumn{4}{|c|}{ Superimposed injections } \\
\hline \multirow[t]{2}{*}{ K52R } & 15 & 31 & Red \\
\hline & 29 & 31 & Green \\
\hline
\end{tabular}

After the appropriate survival period, animals were heavily anesthetized with Nembutal $(50-60 \mathrm{mg} / \mathrm{kg}$, i.p.) and perfused transcardially with $0.1 \mathrm{M}$ phosphate buffer followed by $4 \%$ paraformaldehyde in 0.1 $M$ phosphate buffer. In some animals older than $20 \mathrm{~d}$, fixation was followed by an additional rinse with $0.1 \mathrm{M}$ phosphate buffer to prevent overfixing, which made cortical flattening more difficult. All of the cortex corresponding to area 17 was removed along with surrounding cortex and placed in $0.1 \mathrm{~m}$ phosphate buffer. The remainder of the brain was refrigerated in $4 \%$ paraformaldehyde and $30 \%$ sucrose in $0.1 \mathrm{M}$ phosphate buffer for further fixation and later analysis of geniculate labeling (see below).

The cortical tissue was flattened by a method similar to that described by Tootell and Silverman (1985). Each hemisphere of cortical tissue was flattened separately by carefully cutting the white matter within the cortical folds and finally pressing the tissue between glass slides separated by dental wax and held together with rubber bands. The flattened cortex was fixed an additional 2 or more days between the glass slides in $4 \%$ paraformaldehyde and $30 \%$ sucrose in $0.1 \mathrm{M}$ phosphate buffer. Forty-micron-thick tangential sections were then cut from the flattened cortex with a freezing microtome. Sections were mounted on gelatinsubbed slides, air-dried, cleared in xylene for 10-20 sec, and coverslipped with Fluormount (Gurr). 

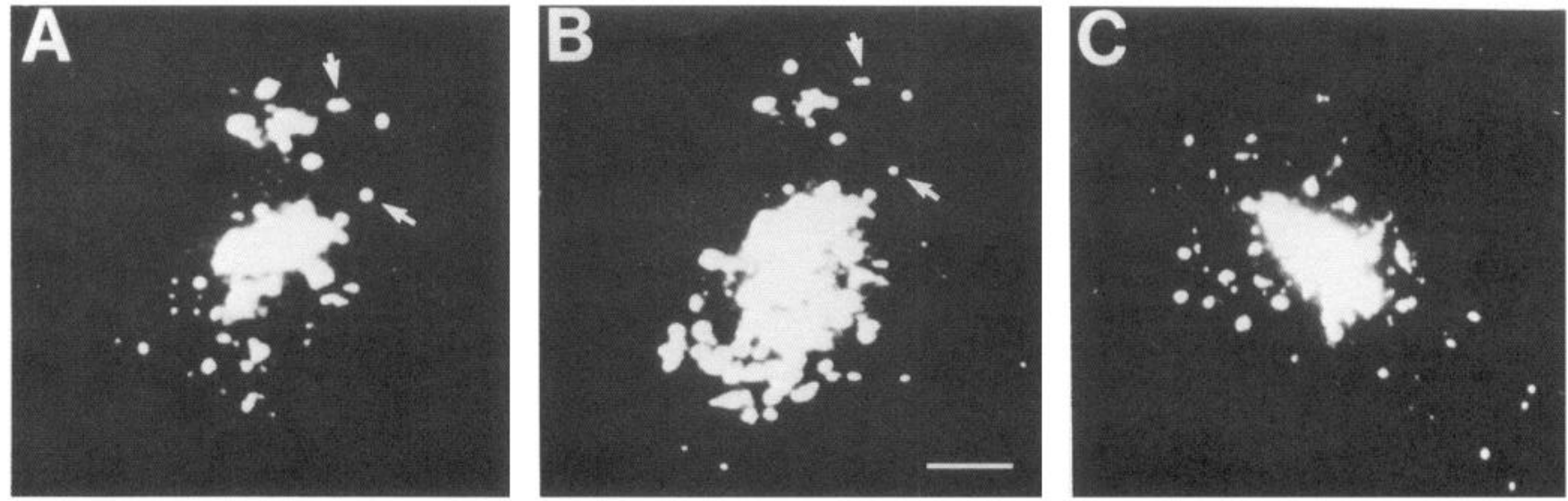

Figure 1. Photomicrographs of fluorescent latex microsphere injection sites in tangential sections of area 17 . Each panel $(A-C)$ depicts a different microsphere injection. The 3 injection sites shown illustrate typical injection sizes and the absence of tracer diffusion. $A$ and $B$, Superimposed red $(A)$ and green $(B)$ injections made on P15 and P29, respectively, at a single location in the same hemisphere (Table 1, K52R). The 2 arrows in each panel point to fluorescent material that was visible with both the rhodamine and fluorescein filter sets, which can be used to align the photographs. Note that the regions of densest microsphere deposition were precisely coincident for these 2 injection sites, but that the later, green injection was somewhat larger than the earlier, red injection (about $320 \mathrm{vs} 200 \mu \mathrm{m}$ from top to bottom). Because the later injection was larger, the more refined pattern of retrograde label resulting from this injection (see Results) cannot be attributed to differences in the sizes of the injection sites. $C$, A third injection site made in area 17 on P6 (hemisphere K57L of Table 1). The diameter of this injection was about $200 \mu \mathrm{m}$. Scale bar, $100 \mu \mathrm{m}$.

Injection sites and the patterns of bead-labeled cells surrounding them were observed with a Zeiss microscope equipped with a mercury lamp and rhodamine and fluorescein filter sets. Camera lucida drawings were made from representative sections for every successful injection. Successful injections were defined as those which (1) resulted in deposition of beads into the cortex, (2) did not penetrate into the white matter, and (3) were confined to area 17.

In order to avoid sampling of sections through layer 4 , where the horizontal intrinsic circuitry differs from that in supra- and infragranular layers in adult carnivores (Gilbert and Wiesel, 1979, 1983; Martin and Whitteridge, 1984; Rockland, 1985), sections chosen for further analysis were restricted primarily to those corresponding to the superficial cortical depths of $240-440$ or $200-300 \mu \mathrm{m}$ in the youngest animals where the superficial laminae are not yet fully developed (Shatz and Luskin, 1986). Layer 5 could be identified in tangential sections by the presence of large pyramidal cells which are abundant in layer 5 but absent from layer 4. Each cell in the section in which microsphere labeling was visible with a $10 \times$, high numerical aperture objective (Wild, $0.45 \mathrm{NA}$ ) was marked on a camera lucida drawing to reveal the complete pattern of label.

For analysis of geniculate labeling, the LGN was removed and cut into $40-\mu \mathrm{m}$-thick sections with a freezing microtome. In the oldest animals (P54 and adult), geniculate sections were cut coronally. Since the mediolateral axis in the LGN maps to the mediolateral axis in area 17 , with the $17 / 18$ border corresponding to the most medial portion of the LGN (Sanderson, 1971), the coronal sections were used to confirm that injections were distant from the $17 / 18$ border (see below). This relation also holds in newborn cats (Henderson, 1982); however, the LGN rotates nearly $90^{\circ}$ in the sagittal plane during the first 8 weeks after birth (Kalil, 1978). Thus, in young cats, in order to obtain sections in which the mediolateral axis was preserved and which, in addition, were cut perpendicular to the geniculate laminae, it was necessary to cut sections in
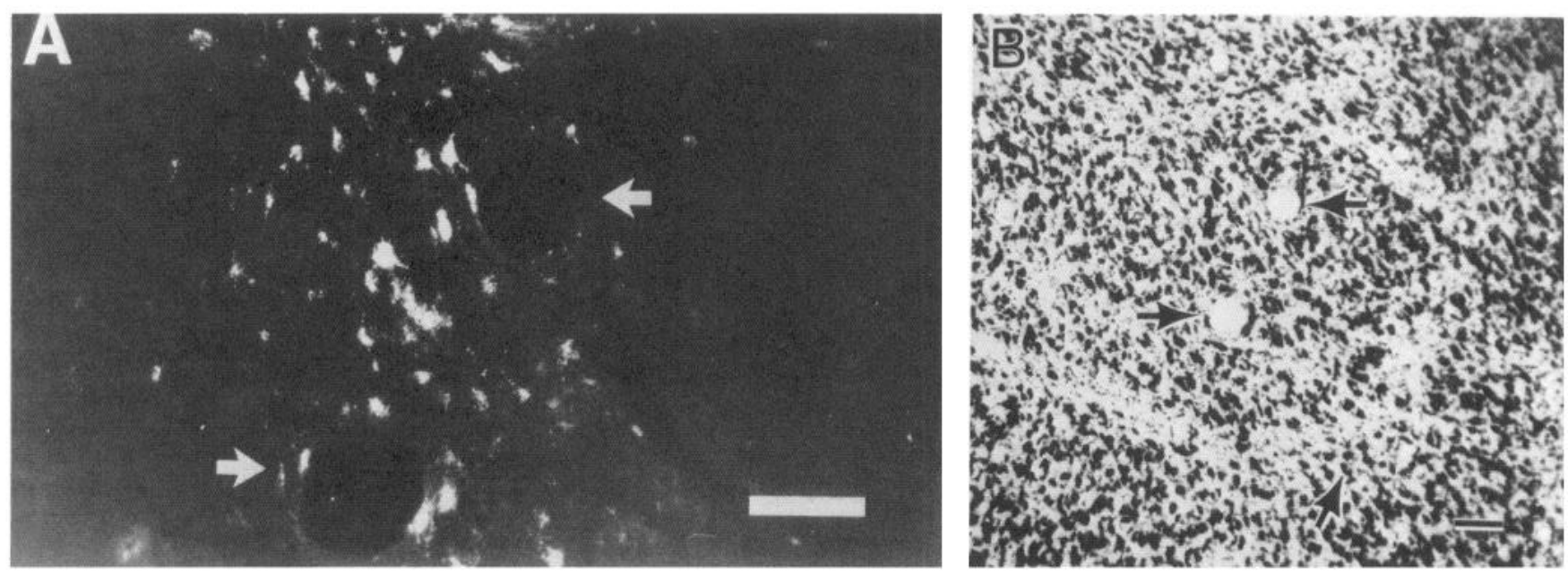

Figure 2. Retrogradely labeled geniculocortical neurons. A, Retrogradely labeled cells in the A1 lamina of the LGN from an animal injected in area 17 with fluorescent latex microspheres on P15 and perfused on P31. B, Lower-power photomicrograph from an adjacent cresyl violet-stained section. Note the 2 large blood vessels indicated by arrows in each panel that can be used to align the 2 photographs. The upper blood vessel is just medial to the densest region of retrograde labeling in $A$ and $300 \mu \mathrm{m}$ from the medial border of the A1 lamina of the LGN, indicated by the arrow at the bottom of $B$. Thus, this injection did not involve the border between cortical areas 17 and 18 . Medial is toward the right side of the figure. Scale bars, $100 \mu \mathrm{m}$. 
different planes. During the first postnatal week, sections were cut near the horizontal plane, and as the characteristic rotation of the LGN progressed, the plane of sectioning was tilted more toward the coronal plane (see Kalil, 1978). Alternate sections were mounted on gelatinsubbed slides, air-dried, cleared in xylene for 10-20 sec, and coverslipped with Fluormount. The remaining sections were mounted and stained with cresyl violet to allow visualization of cell sizes and to identify the medial border of the LGN.

The pattern of retrograde label in a typical LGN is shown in Figure 2 . Figure $2 A$ shows fluorescent-labeled geniculate cells from a cat injected on P15 and perfused on P31, and Figure $2 B$ shows an adjacent cresyl violet-stained section. Note the clear gap between the central densest region of retrograde label and the geniculate's medial border, indicating that the cortical injection was distant from the $17 / 18$ border. The labeling resulting from other microsphere injections was similar in every case but one. For the one case in which the labeling was densest near the medial border of the LGN, the injection site was excluded from our analysis.

Analyzing the positions of retrogradely labeled geniculocortical neurons ruled out injection sites that were near the $17 / 18$ border. The patterns of labeling we observed were expected only from injections confined exclusively to either area 17 or area 18 . It appeared very unlikely that any injection sites in our sample were confined exclusively to area 18 since none were positioned as far laterally as the expected position of area 18 . However, to assure that the injection sites were not in area 18 , we analyzed the sizes of retrogradely labeled cells in the geniculate A laminae and compared them to a sample of all cells in the A laminae of the same hemisphere. Since area 18 projecting cells are relatively large (Hollander and Vanegas, 1977; Geisert, 1980; Henderson, 1982; Price and Blakemore, 1985a, b), we could rule out the possibility that any of the injection sites were confined exclusively to area 18.

To measure the sizes of retrogradely labeled cells and of unlabeled cells in the alternate cresyl violet-stained sections, labeled cells in the $A$ and A 1 laminae of the LGN were identified and the outlines of those cells with visible nuclei were drawn with a camera lucida and $63 \times$ objective. Cells with visible nuclei from corresponding regions in the alternate cresyl violet-stained sections were also drawn. Cross-sectional areas were determined by retracing the cell's outlines with a digitizing tablet interfaced to a computer

Areas of retrogradely labeled cells averaged $125 \pm 5 \mu \mathrm{m}^{2}$ (mean $\perp$ SEM, $n=82$ ), or about $20 \%$ smaller than the average size from the unlabeled population $\left(159 \pm 5 \mu \mathrm{m}^{2}, n=170\right.$; Fig. 3). Since area 18 injections label cells that are on average at least $70 \%$ larger than the unlabeled population (Hollander and Vanegas, 1977; Geisert, 1980; Henderson, 1982; Price and Blakemore, 1985a, b), we conclude that the injection site was not confined to area 18 . Since we had ruled out the possibility that the injection site was at the $17 / 18$ border (see above), we conclude that the injection site was confined exclusively to area 17. Similar results were observed for all of the injection sites included in this study.

A related issue is the determination of the location of the $17 / 18$ border. In tangential sections the normal cytoarchitectonic criteria for identifying the $17 / 18$ border (Otsuka and Hassler, 1962) could not be applied. Since we were interested only in intrinsically labeled cells within area 17 , we did not want to confuse labeled cells within area 18 for area 17 cells. When an area 17 injection was expected based on labeling in the LGN to be within a few millimeters of the lateral border with area 18 , there was either a clear border at which labeled cells stopped or a gap of $1 \mathrm{~mm}$ or greater in which no labeled cells were found (see Fig. 6B). In each case, we believe that the abrupt change in labeling represented the $17 / 18$ border. These findings suggest that contamination of the pattern of intrinsic label by labeled cells in area 18 was unlikely. At any rate, the labeling pattern at regions medial to the injection site (away from the area 18 border) was invariably similar to the pattern lateral to it (toward the area 18 border), and excluding lateral portions of the labeling patterns from our analysis would not alter any of our conclusions.

DiI injections and analysis. Cortical tissuc to be labeled with the fluorescent neuronal tracer DiI (Godement et al., 1987) was perfused, flattened, and fixed further as described above for microsphere-injected material. The tissue was then removed from between glass slides, the pia was peeled from the surface, and a region of cortex along the medial bank was chosen as the injection site. A glass micropipette (tip diameter about $25 \mu \mathrm{m}$ ) was pushed through the entire depth of the tissue (from pia to white matter) perpendicular to its surface to produce a small hole

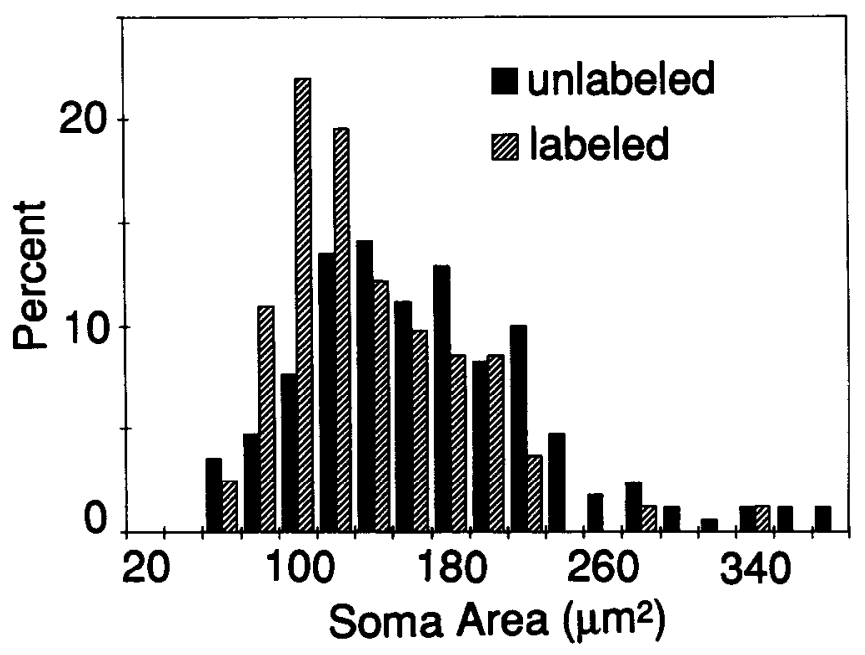

Figure 3. Histogram illustrating the distributions of cross-sectional areas of retrogradely labeled cells (hatched bars) and unlabeled cells (filled bars) in the A and Al laminae of the lateral geniculate nucleus. Results shown are from a single P31 animal in which area 17 was injected with fluorescent latex microspheres on P15. Bins are labeled according to their upper limits in $\mu \mathrm{m}^{2}$ and bar heights represent the percentages of cells included in the bins. The average area for labeled cells was $125 \pm 5 \mu \mathrm{m}^{2}$ (mean $\pm \mathrm{SEM}, n=82$ ), and the average for unlabeled cells was $159 \pm 5 \mu \mathrm{m}^{2}(n=170)$.

into which a fine crystal of Dil was then placed. The tissue was then sandwiched loosely between filter paper and glass slides, immersed in $1 \%$ paraformaldehyde in $0.1 \mathrm{M}$ phosphate buffer, and incubated at $37^{\circ} \mathrm{C}$ for 25-35 d to allow diffusion of the Dil. After incubation, $75-\mu \mathrm{m}$-thick vibratome sections of the tissue were cut tangential to the cortical surface, mounted individually on glass slides, and coverslipped in a 1:1 mixture of glycerol and PBS. Photographs of the sectioned tissue were taken using a Zeiss microscope equipped with standard rhodamine filters.

\section{Intracellular staining}

Most of the procedures used for intracellular recording, staining, and processing and analysis of filled cells were similar to those described previously (Katz, 1987; Katz et al., 1989). In brief, kittens were deeply anesthetized with Nembutal (40-50 mg/kg, i.p.) and placed in a stereotaxic holder. A large craniotomy was made to expose the visual cortex of both hemispheres well beyond area 17 , and the dura overlying the region was removed. From each hemisphere a large portion of the cortical tissue, including the majority of area 17 , was removed and placed in cold, oxygenated artificial cerebral spinal fluid (ACSF; composition in $\mathrm{mM}: \mathrm{NaCl}, 124 ; \mathrm{KCl}, 5 ; \mathrm{KH}_{2} \mathrm{PO}_{4}, 1.25 ; \mathrm{MgSO}_{4}, 2 ; \mathrm{CaCl}_{2}, 3 ; \mathrm{NaHCO}_{3}$, 26; $d$-glucose, 10; kynurenic acid, $2, \mathrm{pH} 7.4)$. After removing the visual cortex, animals were killed by a Nembutal overdose (additional $60 \mathrm{mg}$ / $\mathrm{kg}$, i.p.). The tissue was unfolded, cut into smaller blocks (approx. $5 \times$ $5 \mathrm{~mm}$ ), and sectioned tangentially with a vibratome to a thickness of $350 \mu \mathrm{m}$. These slices were placed in an interface chamber where they were stored for later filling of individual neurons with LY. Only the most superficial slices, containing layers 2 and 3 , were used. The number of cells from each animal included in our analysis was limited by (1) the number of available slices, which was far less than when coronal slices are used; and (2) the requirement that all axons from cells acceptable for further analysis be well filled. The latter requirement was unusually limiting in the present experiments, especially for older animals, since it is difficult to fill axons that project long distances from the cell body.

\section{Results}

Appearance and refinement of intrinsic retrogradely labeled cell clusters

Fluorescent latex microspheres injected into area 17 during the first postnatal week resulted in an unclustered pattern of retro- 


\section{A P5 superficial B $\quad$ P5 deep}

Figure 4. Intrinsic retrograde label at P5 and P8. Panels illustrate patterns of retrogradely labeled cells (dots) and area 17 injection sites (open figures) in tangential sections through superficial $(A$, $C)$ and deep $(B)$ laminae of flattened visual cortex. $A$ and $B$, Labeling in sections from a hemisphere injected with fluorescent latex microspheres on P5 and perfused on P6. C, Labeling from a P8 injection followed by perfusion on P9. The labeling resulting from the P5 injection was not clustered in either the superficial or deep section, while the label resulting from injection at $\mathrm{P} 8$ was very crudely clustered. Two presumptive clusters are indicated by arrows. In this and subsequent figures, directional arrows point anteriorly and a perpendicular line extends medially from the base of the arrow. Scale bar, $1 \mathrm{~mm}$.

grade labeling in tangential sections at all depths, indicating the absence of clustered connections throughout the cortical laminae (Fig. $4, A, B$ ). In addition to the absence of clusters in both superficial and deep laminae, the tangential extent of labeling was similar in the 2 layers. This implies that the lengths of horizontal axon collaterals extended by the deeper cells were similar to those of the superficial cells, despite the fact that the layer 5 cells acquire their final laminar positions many days prior to even the oldest layer 3 cells (Luskin and Shatz, 1985; Shatz and Luskin, 1986).

Figure 5. Intrinsic retrograde labeling 2-3 weeks (12-21 d) postnatally in tangential sections. Injections were made on P12 $(A, B), P 14(C)$, or $\mathrm{P} 21(D)$ and followed by perfusion $1 \mathrm{~d}$ later. For the P12 injection, both superficial $(A)$ and deep sections $(B)$ are shown; the remaining sections are all from superficial laminae. The pattern of labeling in each case was clustered with a periodicity of roughly $1 \mathrm{~mm}$. Note that at these ages clustering was relatively crude (compare with Fig. 6); there were many labeled cells in between the most densely labeled clusters, reflecting 


\section{A}

\section{P12 superficial}

B

P12 deep
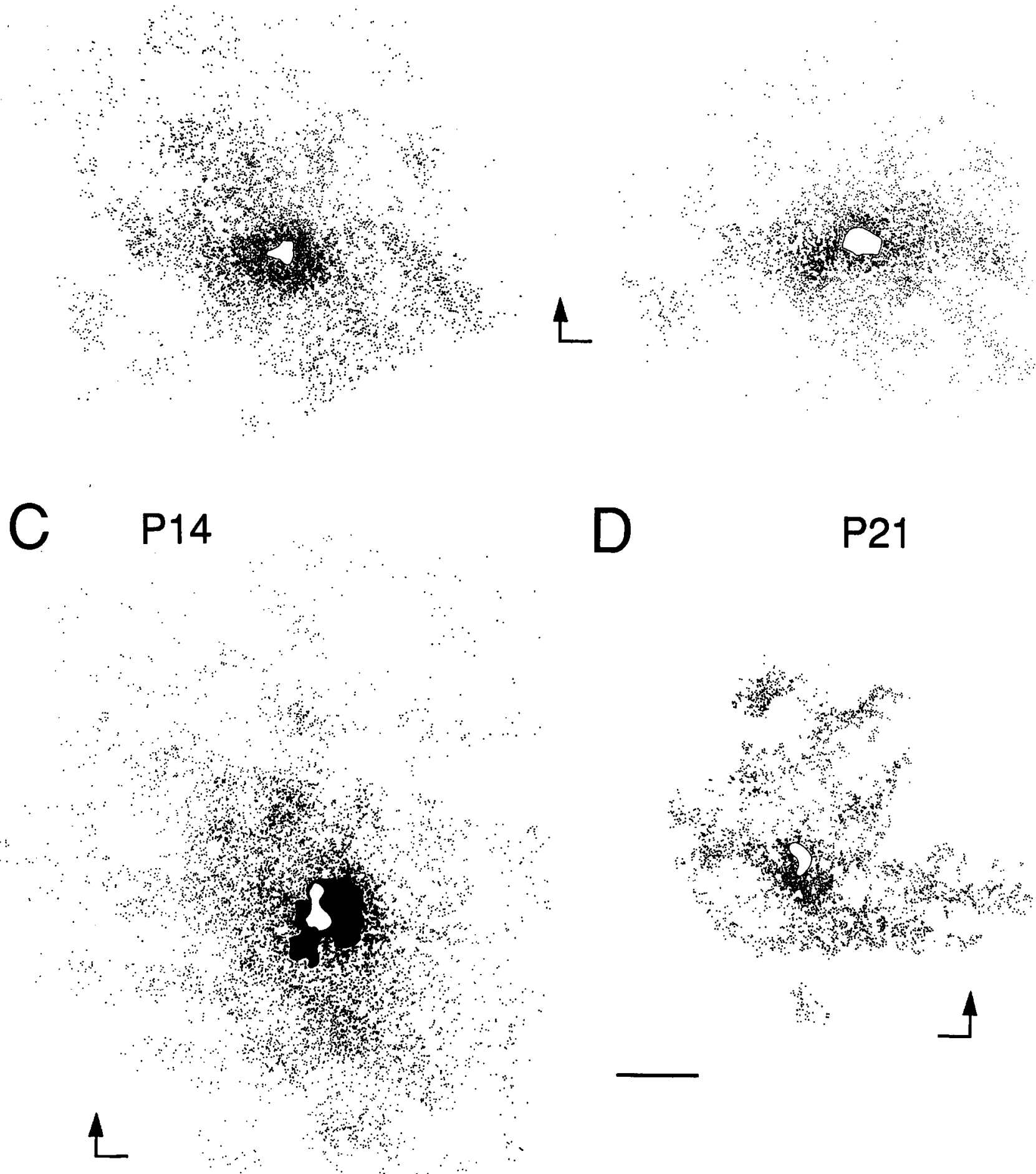
A

P38

B

P38
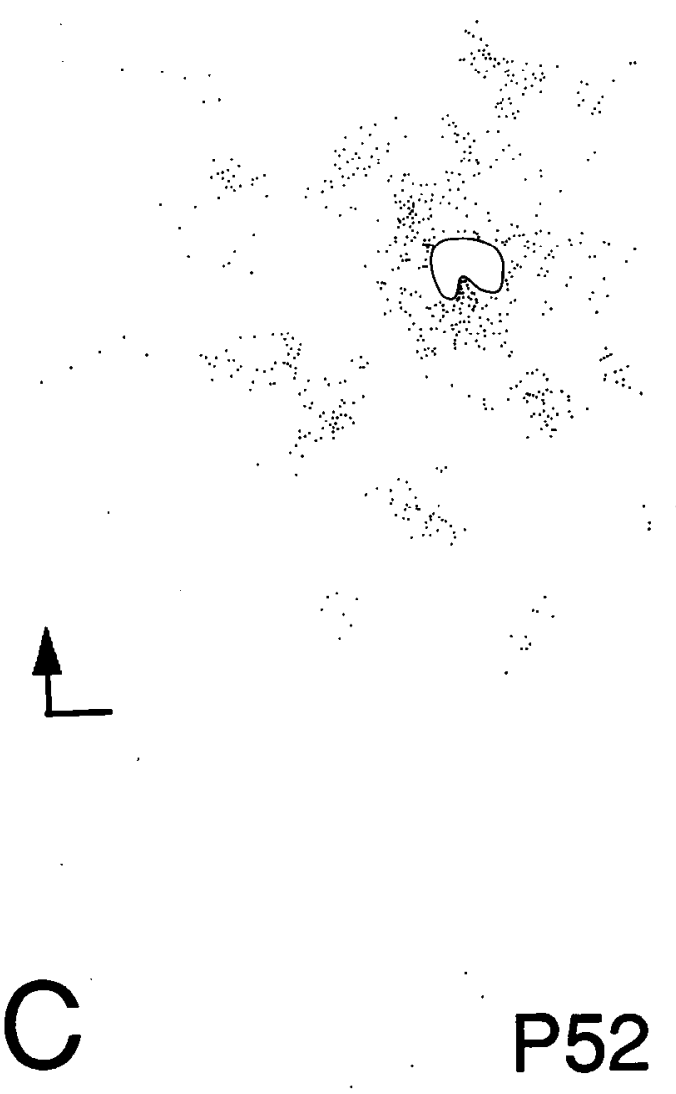

$L$

P52

D
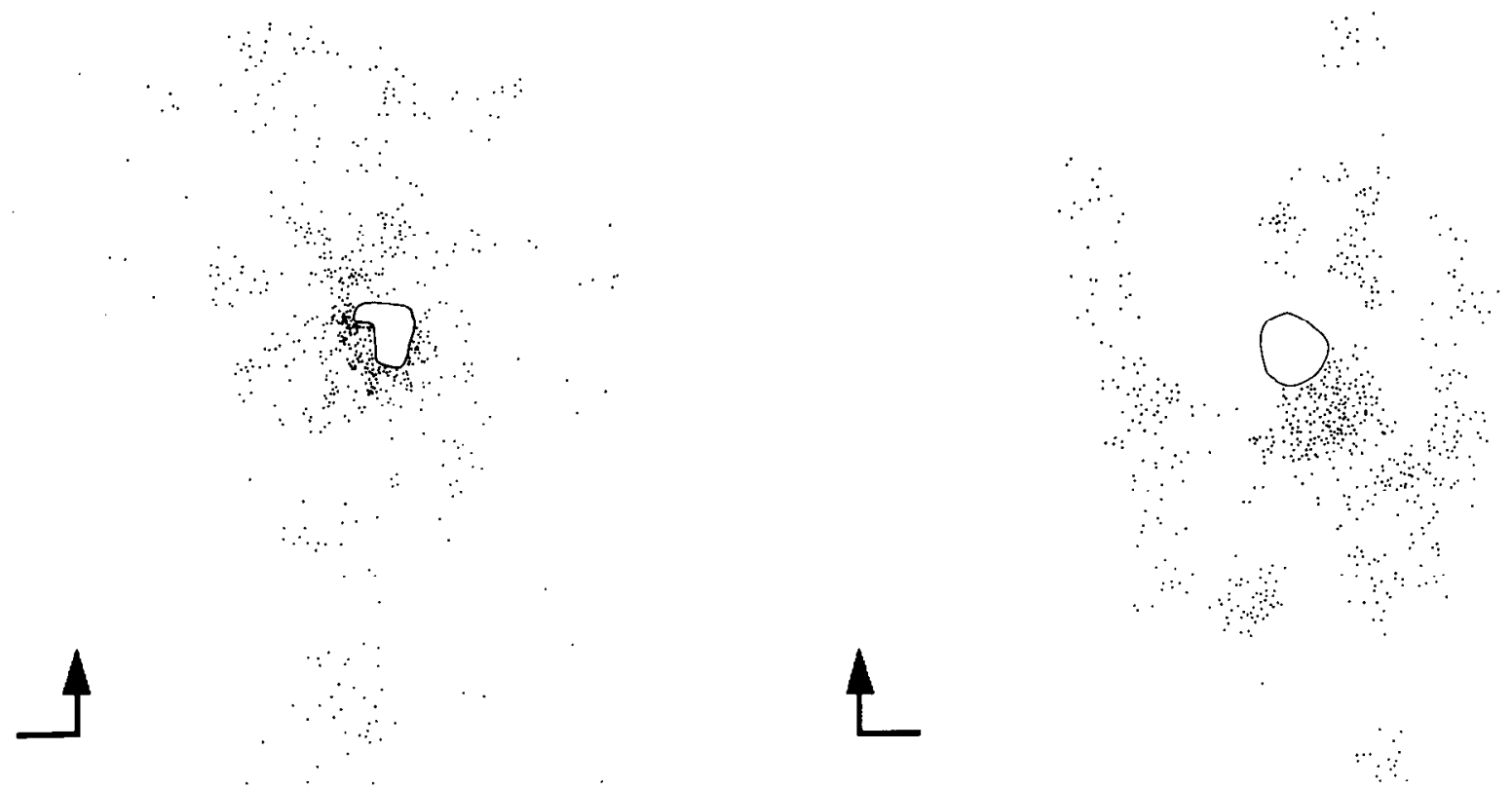

Figure 6. Intrinsic retrograde labeling after the fifth postnatal week (P36-38, $A, B ; \mathrm{P} 52, C$; adult, $D$ ). Injections resulted in a refined pattern of retrogradely labeled cell clusters; individual clusters were separated by gaps containing relatively few labeled cells. The unusually large gap in $B$ between the most lateral column of clusters and the remainder of the labeled cells probably represents the 17/18 border. The gap in labeling anterolateral to the injection site in $D$ corresponds to a tear in the tissue that occurred during flattening. Scale bar, $1 \mathrm{~mm}$. 

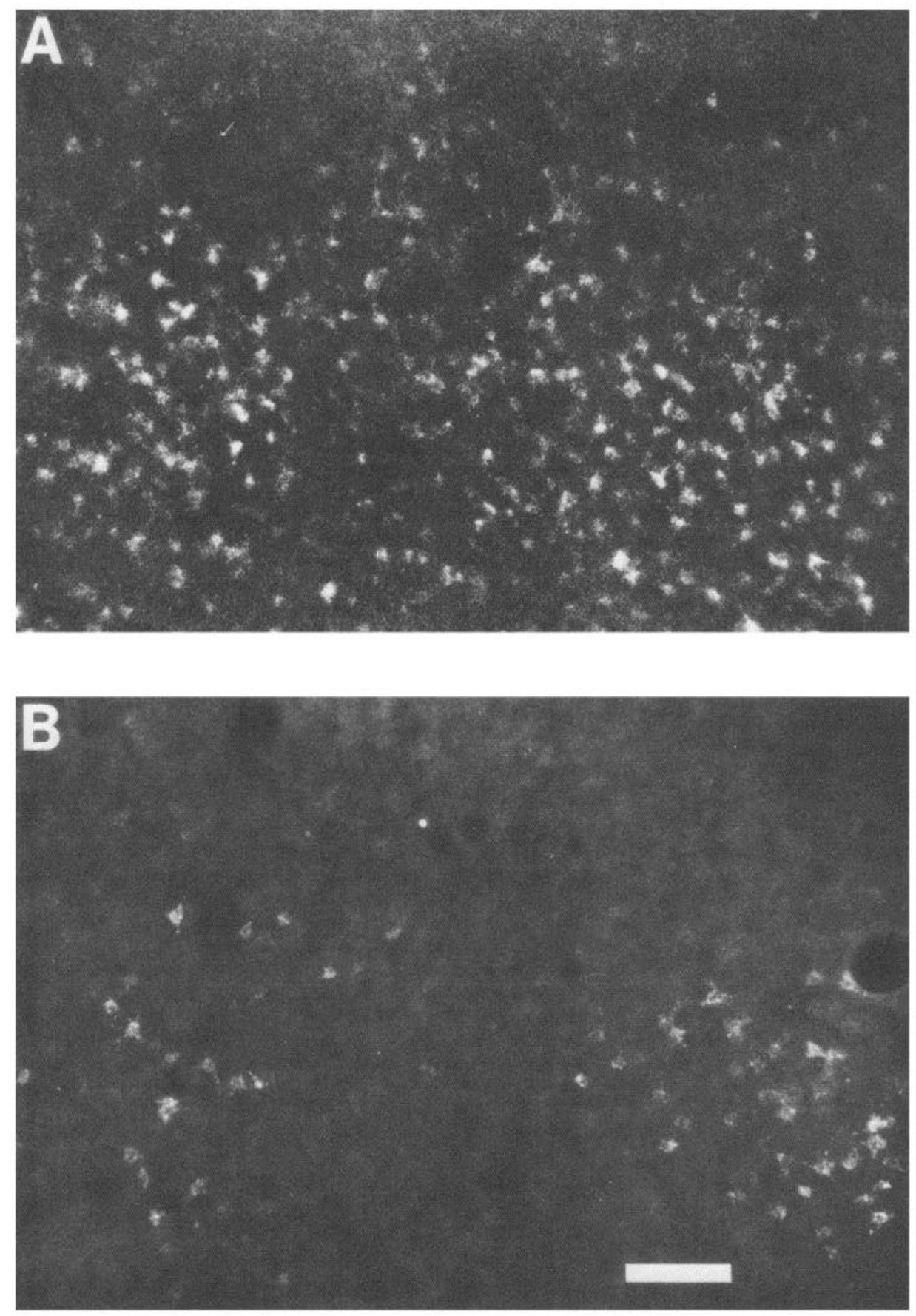

Figure 7. Photomicrographs of clusters of retrogradely labeled cells in superficial layers. $A$, Labeling in a tangential section following a microsphere injection at P12. B, Label following a microsphere injection at P38. Two clusters of retrogradely labeled cells are apparent in each panel. The earlier injection $(A)$ resulted in crude clustering-many labeled cells occupied the space between clusters - while the clusters resulting from the later injection $(B)$ were more refined-very few cells between the clusters were labeled. Scale bar, $100 \mu \mathrm{m}$.

At P8 the pattern of labeling was no longer uniform (Fig. 4C). Presumptive clusters were discernible in all layers, and clustering was more obvious among the cells that were further away from the injection site. We infer that the axons that transported label to the most distant cells were longer than most of those that were present at P6, suggesting that the formation and/or maintenance of connections had become selective. The simultaneous appearance of clusters in superficial and deep layers suggests that this transition may be triggered by a common mechanism for cells in the different layers despite the difference in postmigratory age for the 2 populations.

Microsphere injections during the late second and third postnatal weeks resulted in an increasingly clustered pattern of retro- gradely labeled cells (Fig. 5, $A-D$ ). Both the extent of label and degree of clustering remained similar in superficial and deep laminae ( $c f$. Fig. 5, $A$ and $B$ ). At these ages, clusters were not yet well defined; despite the regions of dense label corresponding to "clusters," there were still many labeled cells between clusters (cf. Figs. 5 and 6, and Fig. 7, $A$ and $B$ ). The centers of clusters were spaced about $1 \mathrm{~mm}$ apart, a value similar to that observed in the adult. The most distant labeled cells in superficial sections resulting from the 7 injections at these ages ranged from 2.4 to $4.2 \mathrm{~mm}$ from the injection site along the anterior-posterior (AP) axis (mean $\pm \mathrm{SEM}=3.4 \pm 0.3 \mathrm{~mm}, n=7$ ) and $1.9-4.0 \mathrm{~mm}$ along the mediolateral (ML) axis $(2.7 \pm 0.3 \mathrm{~mm}, n=7)$.

By the sixth postnatal week (P36-38), the pattern of intrinsic 


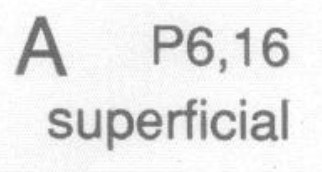

Figure 8. Intrinsic retrograde label resulting from P6 injections followed by perfusion on P16. $A$ and $B$, Labeling in tangential sections through superficial and deep layers from the same animal. $C$ and $D$, Labeling from superficial and deep layers in a second animal. The retrogradely labeled cells are not clustered for either injection site in either superficial or deep layers. Scale bar, $1 \mathrm{~mm}$. retrograde label following microsphere injections was indistinguishable from that in the adult ( $c f$. Fig. $6, A, B$ with $C, D)$. The principal change between the second and fifth postnatal weeks was a reduction in the number of cells lying between clusters (cf. Figs. 6, $A, B, \mathrm{P} 36-38$, to $5, A-D, \mathrm{P} 12-21$, and $7, A$ to $B$ ). After the fifth postnatal week, the clusters were smaller and the spaces between them were almost devoid of labeled cells. These results suggest that cells between clusters that are labeled by the earlier injections project inappropriately to the injection site and subsequently either die or selectively eliminate incorrect connections.

The distances from the injection site to the furthest labeled cells in the sixth postnatal week (P36-38) ranged from 2.5 to $4.2 \mathrm{~mm}$ along the AP axis $(3.5 \pm 0.4 \mathrm{~mm}, n=4)$ and from 1.7 to $3.9 \mathrm{~mm}$ along the ML axis $(2.7 \pm 0.5 \mathrm{~mm}, n=4)$. The values for extent of label from our 2 adult injections were 2.2 and 2.8 $\mathrm{mm} \mathrm{AP}$, and 1.9 and $1.6 \mathrm{~mm} \mathrm{ML}$. Although these distances were somewhat shorter than the corresponding means obtained during the third and sixth weeks after birth (P12-21 and P3638 ), they are within or near the ranges observed at those ages. Thus, given the small sample, these differences probably arise from random variation. In support of this hypothesis, Gilbert and Wiesel (1989), using identical techniques in adult cats, observed microsphere labeling extending 3.2 and $4.5 \mathrm{~mm} \mathrm{AP}$, and 2.4 and $3.2 \mathrm{~mm}$ ML. Pooling the values from all 4 adult animals resulted in means of $3.2 \pm 0.5 \mathrm{~mm} \mathrm{AP}$ and $2.3 \pm 0.35 \mathrm{~mm}$ ML. None of the mean values from injections during the third week (P12-21), sixth week (P36-38), or in adult animals varied 


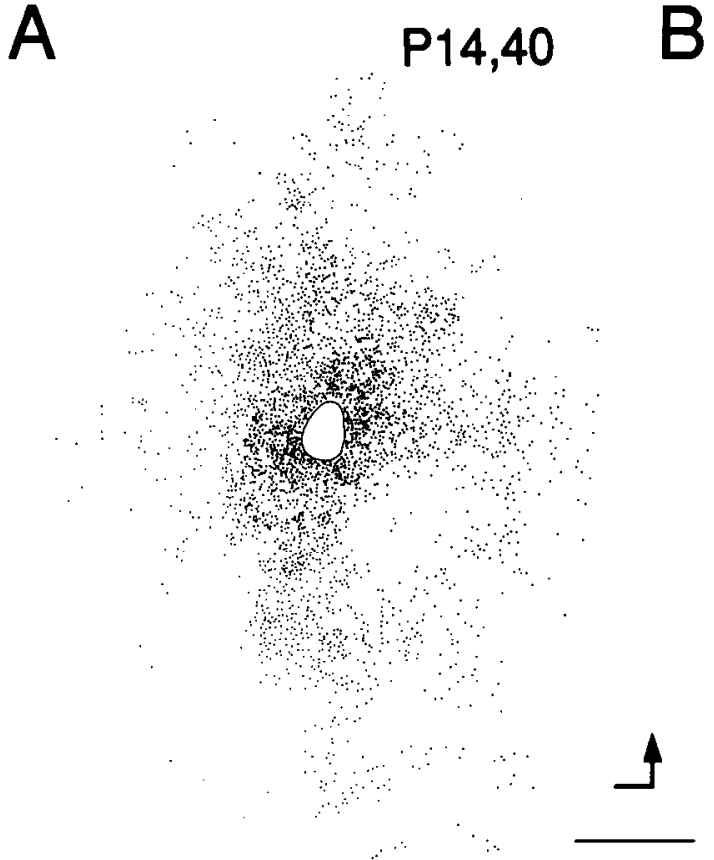

significantly from any other along the same axis $(p>0.1$, Student's $t$ test).

Pairwise comparisons do reveal a tendency for more extensive AP than ML labeling at all ages, in agreement with previous investigations (Luhmann et al., 1986; Gilbert and Wiesel, 1989). The AP extent is greater than the ML extent for 6 of 7 injections at P12-21 and for all of the P36-38 (4 of 4) and adult (4 of 4) injections.

\section{Role of cell death in cluster development}

Experiments with longer survival times after injections were done to examine the possible role of cell death in the formation and refinement of clusters. In one set of experiments, microsphere injections were made during the first week (at P6) and animals killed after the second week (at P16). In another set, animals were injected at the start of the third postnatal week (at P14-15) and killed during the sixth week (at P38-40; see Table 1, delayed perfusion). The early injections tested whether cell death contributed to the transition from an unclustered to a crudely clustered distribution of labeling, and the later injections tested whether cell death contributed to cluster refinement.

Figure $8, A-D$, illustrates results from 2 early injections; superficial $(A, C)$ and deep $(B, D)$ sections are shown. As in the short survival experiments done during the first week, there was no clustering of labeled cells around the injection sites in any layer. Furthermore, the sizes of the labeled areas were similar to that observed $1 \mathrm{~d}$ after P5 injection (compare to Fig. 4, $A$, $B)$. Thus, we conclude that selective cell death was not responsible for the appearance of crude clustering at the end of the second postnatal week (P12-14) in either superficial or deep layers.

Similarly, injections in older animals that were followed by long survival times (P14-15 injection, P38-40 perfusion) also exhibited the pattern of labeling characteristic of the age at the time of injection (Fig. 9, $A, B$ ). In these cases, labeled cells were

\section{$P 15,38$}

Figure 9. Intrinsic retrograde label resulting from injections at the end of the second postnatal week (P14-15) followed by perfusion during the sixth week (P38-40). Each panel depicts the labeling from a different injection site in a tangential section through superficial laminae. While there were some indications of clustering in both examples, neither injection resulted in the refined pattern of clustering observed after the fifth postnatal week (Fig. 6). The labeling in these cases resembled that observed following injections during the second postnatal week (Fig. 5) or was perhaps even less clustered. Scale bar, $1 \mathrm{~mm}$. crudely clustered compared with the adultlike labeling observed following microsphere injections during the sixth week (at P3638, Fig. 6, $A, B$ ); many labeled cells between clusters persisted. In fact, the clustering appeared less refined than that observed in animals injected at the end of the second week (P12-14) and perfused the next day (Fig. 5, $A-C$ ). We conclude from these results that selective cell death did not contribute to the transition from crude clustering to adultlike refined clusters.

\section{Role of process elimination in cluster refinement}

We have described the refinement of retrogradely labeled cell clusters as a reduction in the proportion of cells between clusters that make inappropriate connections to the injection site. Injections followed by long survival demonstrated that this change was not due to selective cell death. Thus, a third type of experiment was done to test directly whether cluster refinement occurred by the selective elimination of inappropriate projections. An injection of red microspheres was made in area 17 prior to cluster refinement (at P15) and then an injection of green microspheres was made later in development (on P29) at precisely the same location (see injection sites in Fig. 1, $A, B$ ). The animal was perfused at $\mathrm{P} 31$. If process elimination does contribute to cluster refinement, this experiment should result in many between-cluster cells labeled by the early injection but not by the later injection; and cells labeled by both injections should be in "refined" clusters.

The results from this experiment are illustrated for a superficial section in Figure 10. Cells labeled by the early (P15) injection were arranged in the crude clusters typical of this age (e.g., Fig. 5, $A-C$ and 9, $A, B$ ). The double-labeled cells-those that projected to the injection site at $\mathrm{P} 15$ and retained a projection past $\mathrm{P} 29$ - were arranged in a refined adultlike patlem of clusters. These clusters were centered in the densest regions of crude (P15) clusters. Thus, many cells that projected inappropriately to the injection site at P15 and were still surviving 


\section{P15,29,31}

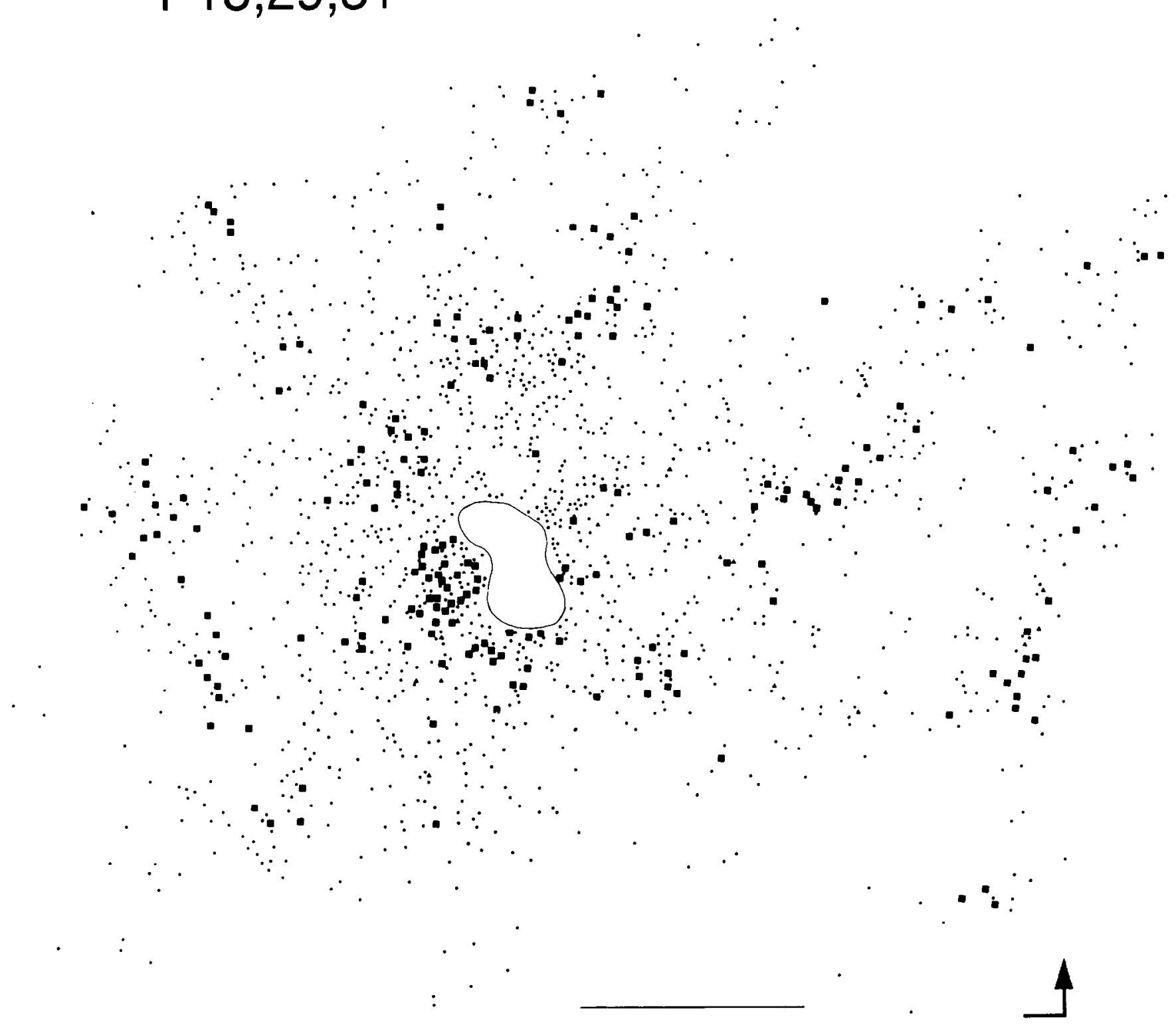

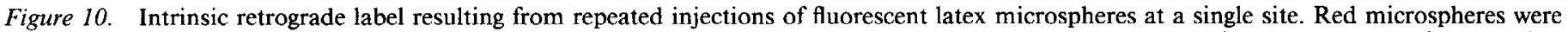

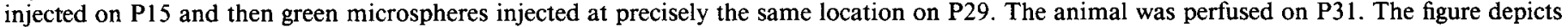

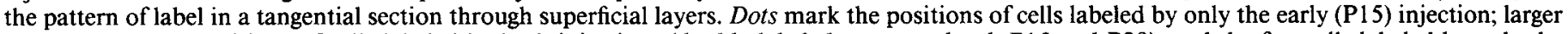

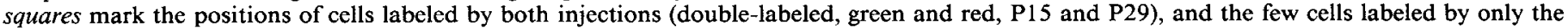

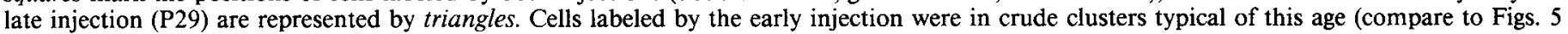

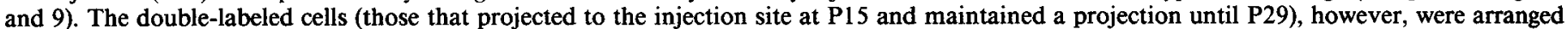

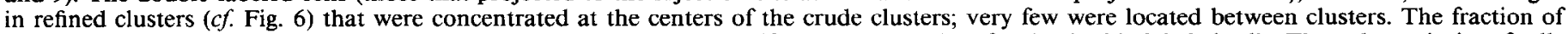

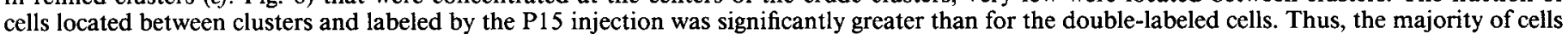

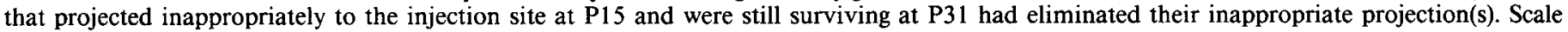
bar, $1 \mathrm{~mm}$.

at P31 did not project to the injection site after P29. We conclude that these are cells which eliminated one or more inappropriate connections to the injection site.

Although this experiment demonstrated that many cells lost an inappropriate connection to the injection sitc, it did not directly reveal whether this process was "specific." For example, a nonspecific elimination of axon collaterals (either naturally occurring or induced by damage during the original injection) might have contributed to the more refined appearance of clusters. We were able to distinguish between nonspecific and specific elimination using a more quantitative approach. Nonspecific collateral elimination would not distinguish between cells making correct versus incorrect projections to the injection sitc, and thus such a process should not change the proportion of cells outside of clusters labeled by the early versus the late injection. Specific elimination would decrease the proportion of 


\section{P16}

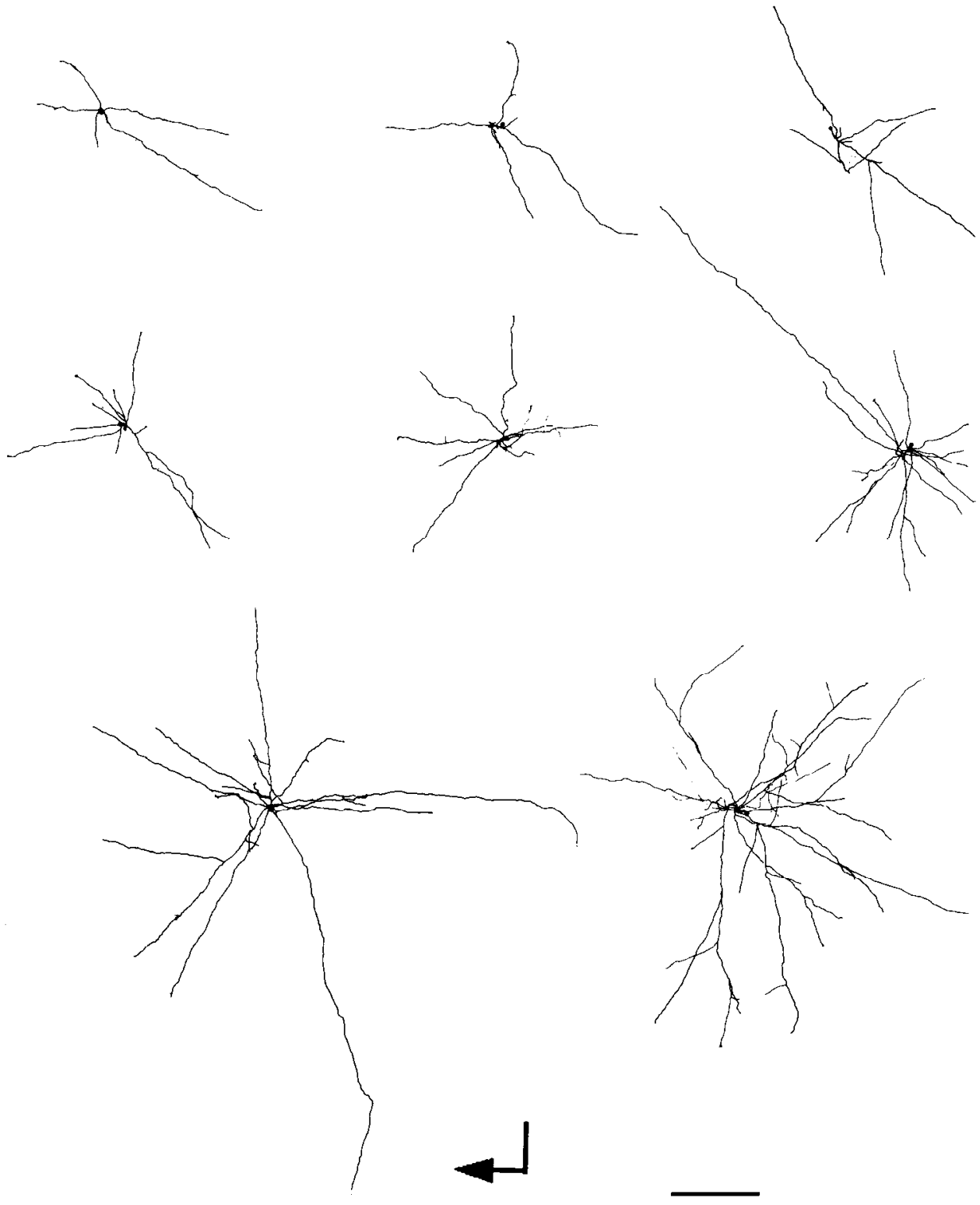

Figure 11. Horizontal axonal arbors of pyramidal cells from superficial layers of striate cortex at P16. The complexity of cells observed at this age varicd considerably. The simplest cells $(t o p$ left) had only a few horizontal collaterals, and although some of the collaterals were rather long ( $>500 \mu \mathrm{m})$, secondary branches were rare. The most complex cells at this age (bottom of figure) had substantially more and longer horizontal collaterals, but these remained relatively unbranched. Clustering of axonal arbors at this age was not apparent. Scale bar, $200 \mu \mathrm{m}$. labeled cells outside of clusters. To measure this proportion for both P15-labeled cells and double-labeled cells, we drew cluster boundaries and counted the numbers of cells within and outside the boundaries. Regardless of the exact position of cluster boundaries (so long as obvious clusters with typical spacing were preserved), the same result was obtained. Thus, we report here the numbers counted for the boundaries that were most liberal with respect to P15 clusters (relatively few cells outside clusters) and that were also most conservative for double-labeled cells. Thirty-three percent (350/1076) of the cells labeled at P15 were outside of clusters, whilc only $11 \%(16 / 130)$ of the doublc-labeled cells were outside of clusters. This difference is highly significant ( $p \ll 0.001, \chi^{2}$ analysis). We therefore conclude that specific elimination of inappropriately projecting axons con- tributes significantly to the refinement of retrogradely labeled cell clusters.

\section{DiI injections}

Results from DiI injected hemispheres were consistent with those obtained following microsphere injections but revealed anterogradely labeled axons as well as retrogradely labeled cell bodies (not shown). Labeling at P6 was unclustered while by P15 clustering of both cell bodies and axons was discernible. The centers of clusters were separated by distances similar to thosc obscrved with retrograde-labeling following microsphere injections, but clusters were not well defined. In particular, heavy labeling between clusters persisted. Clustering was more refined by P31 and indistinguishable from adult labeling at P38-39 and 
P23
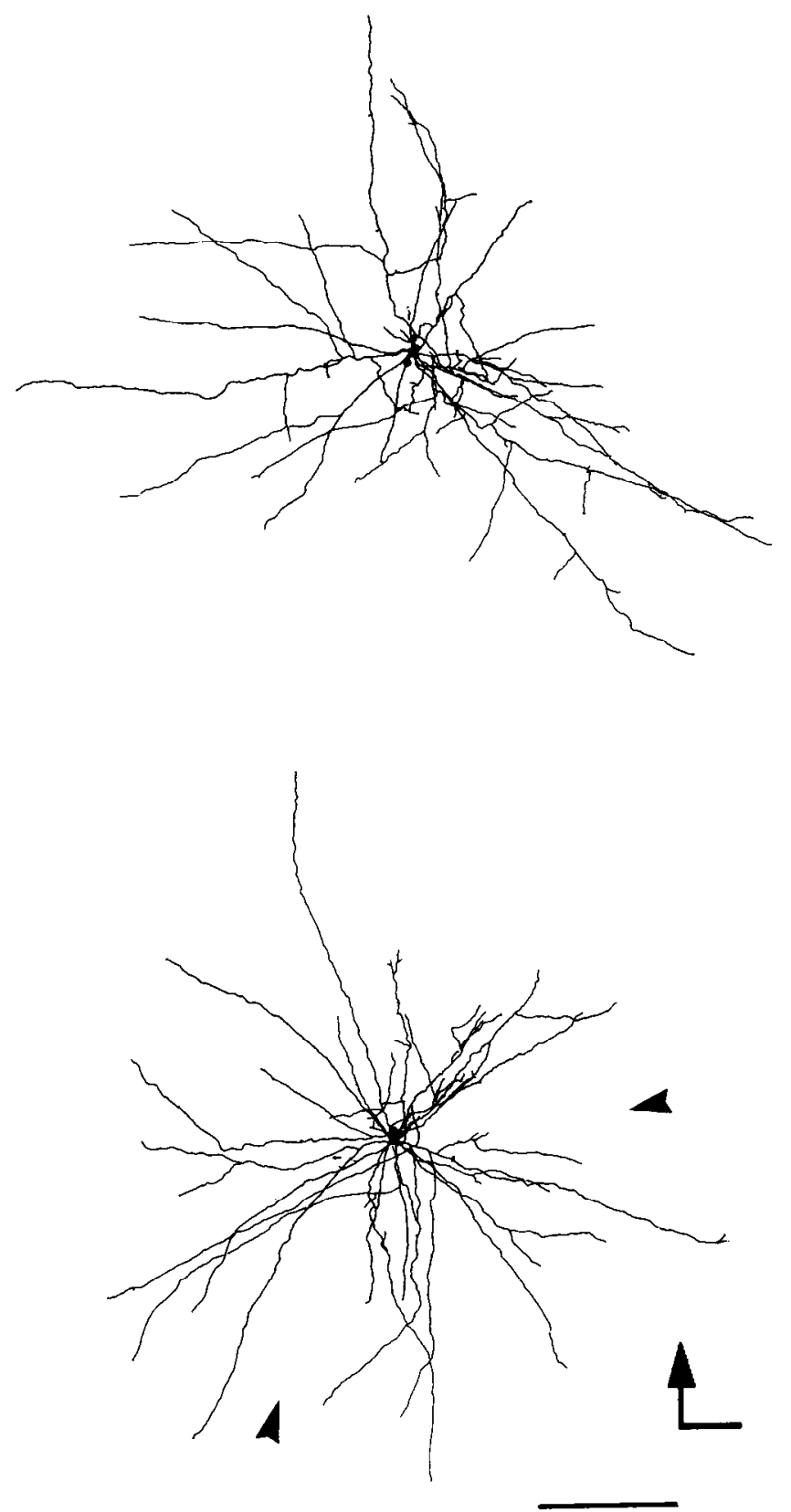

Figure 12. Horizontal axonal arbors of pyramidal cells from superficial layers at P23. The numbers of horizontal collaterals projecting from near the cell bodies were greater at this age than at any other age studied. The cells depicted each had roughly 30 such collaterals, twice as many as observed for even the most complex cells at P16. However, the horizontal collaterals remained relatively unbranched; a few short, finer branches were apparent for some cells. In some cases, gaps began to appear between horizontal collaterals, as indicated by arrows for the cell at the bottom of the figure. Development of horizontal axonal arbors during the third postnatal week appeared to consist primarily of an increase in the number of long horizontal axon collaterals extending from near the cell body and secondarily of the elaboration of a few shorter branches from some of those collaterals. Scale bar, $200 \mu \mathrm{m}$.
P54. Despite extensive diffusion of DiI around the injection sites, clusters were separated by distinct gaps with relatively sparse label. At all ages labeling was similar, both in extent and degree of clustering in superficial and deep laminae, and regions of dense anterograde and retrograde label were coincident.

\section{Development of horizontal axonal arbors}

Horizontal axonal arbors of layer $2 / 3$ pyramidal neurons filled with LY in in vitro tangential slices of superficial cortex were examined at 4 ages: P16, P23, P30, and P43. The numbers and lengths of axons in this sample probably underestimated the true values because the portions of neurons that could be observed were limited to branches within the $350-\mu \mathrm{m}$-thick tangential slices. The actual axon lengths were better estimated based on the patterns of retrograde label observed in microsphere-injected hemispheres (see above). The results of LY fills provided detailed information about the patterns of branching of individual axonal arbors (especially at regions near the cell body), as well as revealing gross quantitative differences between populations of different ages.

Figure 11 shows a representative sample of axonal arbors of cells filled with LY at P16. Neurons filled at this age invariably had many long horizontal axon collaterals extending either from the thick descending main axon trunk or from secondary branches near the cell body. Collaterals branched rarely, if at all, at points distant from the cell body. There was considerable variability in the number of collaterals extending from near the cell body at this age. For example, the relatively simple arbor at the top left of Figure 11 consisted of only 5 such collaterals, while the most complex cells had 10-15. These differences in complexity may correspond to more mature neurons deep in layer 3 versus less mature neurons located more superficially.

Despite the fact that retrogradely labeled cells were noticeably clustered by $\mathrm{Pl6}$, the axonal arbors at this age did not give a clear impression of clustering. This implies that some bias in connectivity existed that was not apparent based on observation of a relatively small number of individual axonal arbors. For example, neighboring cells with roughly symmetric arbors could all project in similar directions, thus leading to clustering of populations of neurons. The absence of obvious axon clustering could also occur if branching of collaterals was not required to form an early, retrogradely labeled crude cluster. Instead, local increases in synaptic density on these simple collaterals, without an increase in branching, might be the first stage in cluster formation.

At P23 cells with only a few collaterals extending from near the cell body were no longer observed. Cells typically had large numbers of horizontal collaterals, as depicted for 2 cells in Figure 12 . These cells each had about 30 collaterals radiating from near the cell body, twice as many as observed for even the most complex cells at P16. These collaterals, however, remained relatively unbranched, simply extending horizontally from the cell body. Clustering of collaterals at this age was still not obvious. However, some cells, such as the one at the bottom of Figure 12 , had gaps in their arbors (indicated by arrows), with several of the collaterals bunched together on each side of the gap. The transition from P16 to P23 is probably most simply expressed as an increase in the number of axons extending from near the cell body, with little increase in the complexity of branching patterns more distally.

By P30, the number of collaterals extending from near cell bodies had decreased. The 4 cells illustrated in Figure 13 each 


\section{P30}
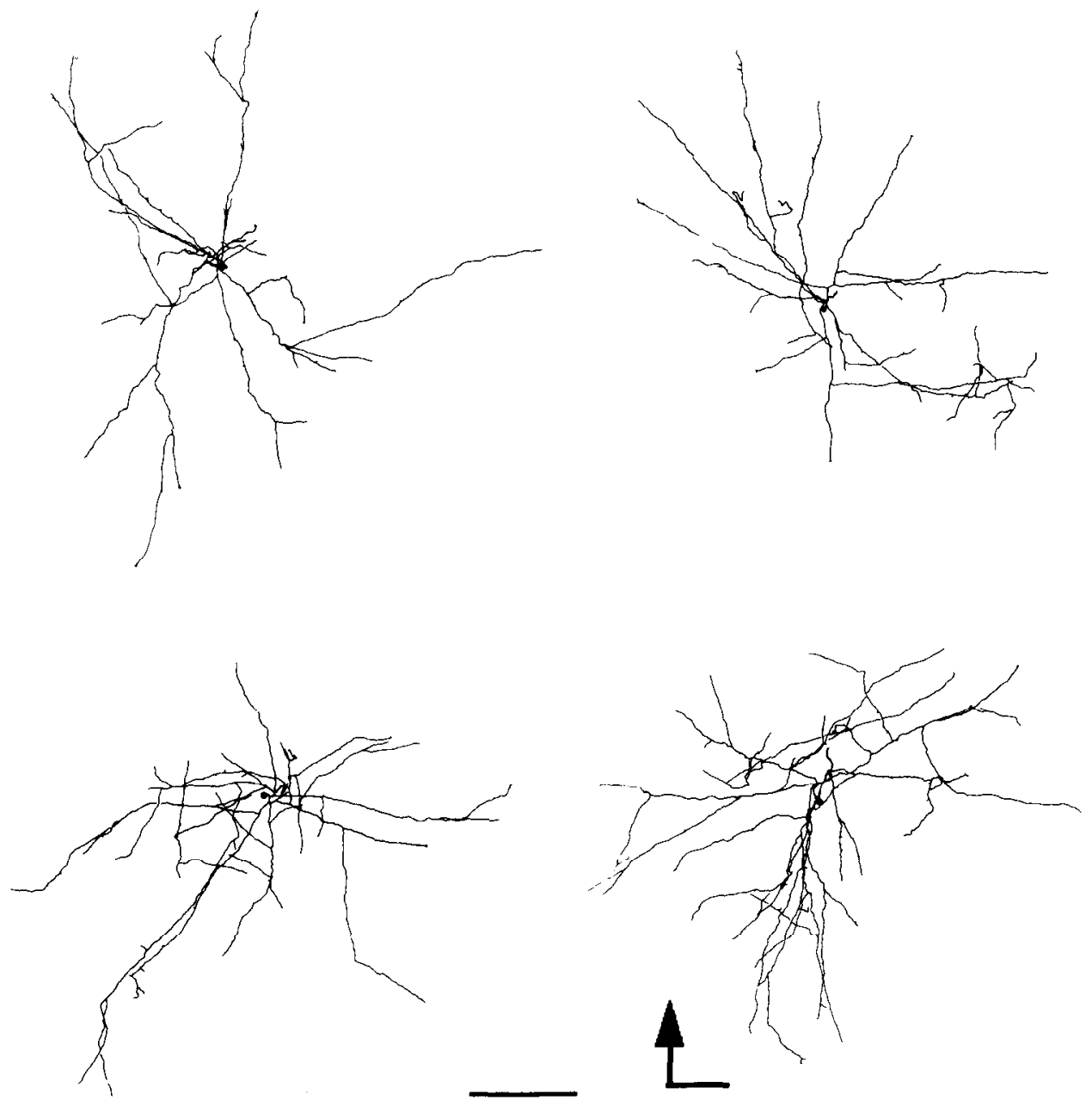

Figure 13. Horizontal axonal arbors of pyramidal cells from superficial layers at P30. The horizontal axonal arbors at this age took on a clustered appearance. The numbers of collaterals projecting from near the cell bodies were reduced compared with the numbers at P23 and those that remained tended to be grouped together. Immature clusters of finer axon branches were also present along or at the ends of some of the collaterals. Scale bar, $200 \mu \mathrm{m}$.

had about 15 such collaterals, roughly half the number observed at P23. In some cells, there was also an increase in distal branching from some of the long horizontal collaterals. Thus, the arbors of most P30 neurons appeared to be clustered. The clustered appearance was due in some cases to "gap" regions surrounded by more concentrated regions of long, horizontal collaterals and in some cases to regions of heavier distal branching. Taken in combination with the results from retrograde labeling, the more clustered appearance at this age relative to $\mathrm{P} 23$ probably resulted from the selective removal of collaterals extending to inappropriate regions as well as from the addition of branches within appropriate regions.

At P43 (Fig. 14), the morphology of horizontal axonal arbors was similar to that reported for the adult (Gilbert and Wiesel, 1979, 1983; Martin and Whitteridge, 1984). The number of long, horizontal collaterals and their association in bundles was similar to that observed at P30. The major change was the elaboration of dense branches at the ends of collaterals or at periodic intervals at more than one point per collateral. Since (1) microsphere injections indicated that few collaterals projected to inappropriate regions after the fifth postnatal week, (2) DiI results indicated that anterogradely and retrogradely labeled clusters were coincident at all ages, and (3) it has been shown that long horizontal collaterals interconnect regions of similar orientation selectivity (Gilbert and Wiesel, 1989), it follows that the collateral branches in the P43 cells were restricted to appropriate target regions, thus linking the cells with others having similar orientation selectivity. The transition from P30 to P43 apparcntly involved extensive branching of collaterals already interconnecting appropriate target regions, specifically within those appropriate regions.

\section{Summary}

Clustering of intrinsic horizontal connections in cat striate cortex first emerged during the second postnatal week from an initially unclustered pattern. The timing of this emergence was similar for cells in superficial and deep laminae. The initially crude clustering was subsequently refined during the third through fifth weeks by the selective removal of axons projecting to incorrect targets. Cell death did not contribute to either the appearance of early crude clusters or to their subsequent refinement. Horizontal axons branched extensively within appropriate target regions only after a relatively simple axonal framework had been confined to correct regions by the selective removal of incorrectly projecting axons. Figure 15 summarizes this process in terms of the expected developmental changes in the 
Figure 14. Horizontal axonal arbor of a pyramidal cell from superficial laycrs at P43. Numbers of horizontal collaterals projecting from near cell bodies at this age were similar to numbers at P30. However, there was a striking increase in the number of secondary and finer branches at periodic intervals. These changes gave the horizontal axonal arbors at this age a much more clustered appearance that was similar to arbors observed in adult animals. Scale bar, $200 \mu \mathrm{m}$.

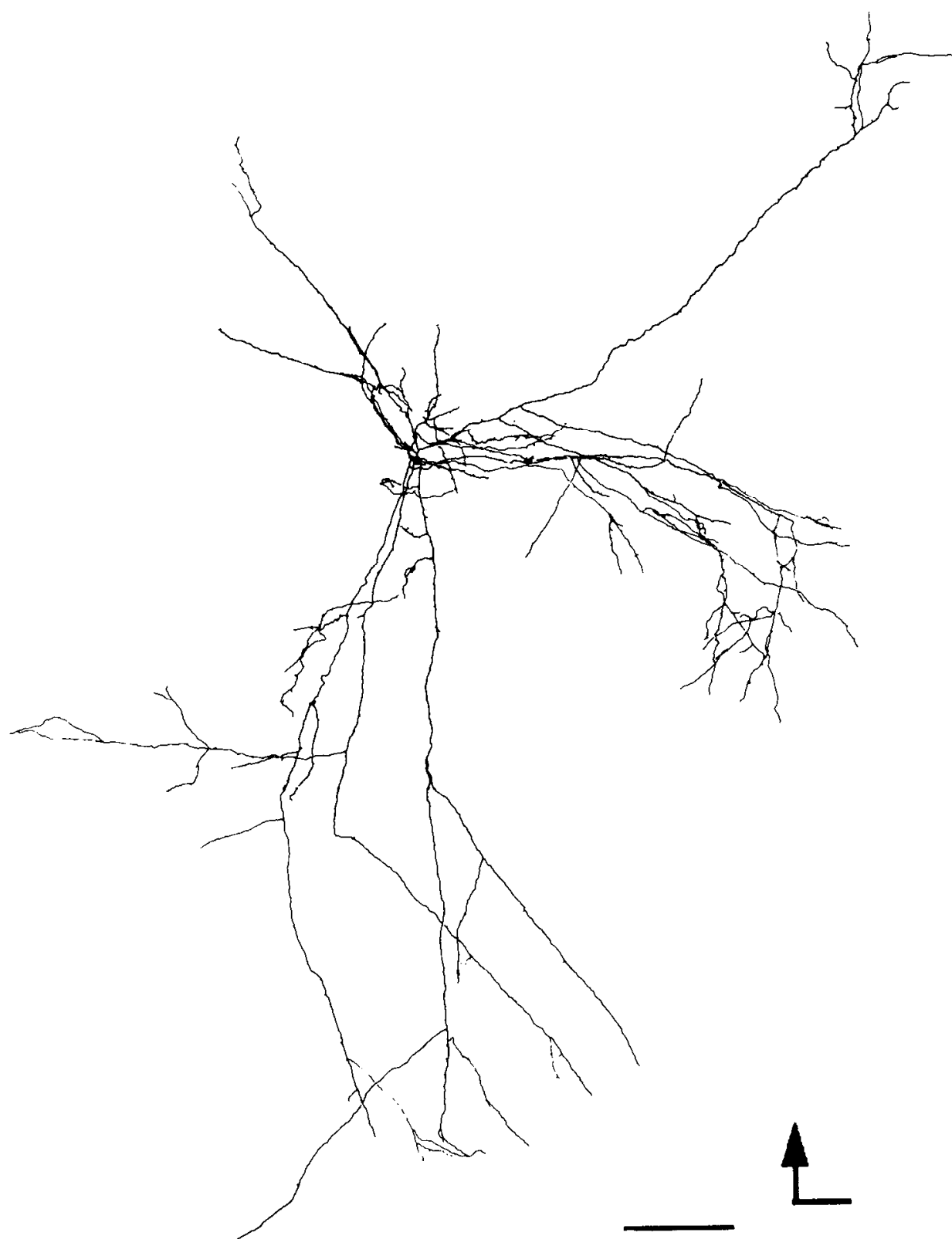

pattern of axonal arborization for a single cell and the relationship of that arbor to presumptive orientation columns.

\section{Discussion}

Exuberant axonal outgrowth or overproduction of neuron populations followed by specific regressive phenomena have emerged as common strategies in the postnatal development of both the central and peripheral nervous systems (see Purves and Lichtman, 1985, for review). Cortical neurons making transient "inappropriate" connections have been observed in the development of both inter- and intrahemispheric corticocortical connections (Innocenti and Caminiti, 1980; O'Leary et al., 1981; Price and Blakemore, $1985 \mathrm{a}, \mathrm{b}$ ) and projections to subcortical targets (Stanfield and O'Leary, 1985; O'Leary and Terashima,
1988). For example, visual cortical neurons near representations of the vertical meridian maintain callosal connections into adulthood, while such connections are entirely eliminated by neurons whose positions correspond to more peripheral parts of the visual field (Innocenti and Caminiti, 1980; O'Leary et al., 1981). In addition, visual cortical neurons project only transiently to the spinal cord, while those in motor cortex maintain this connection (Stanfield and O'Leary, 1985; O'Leary and Terashima, 1988). Similar developmental strategies are also used in the development of connections from retinal ganglion cells. At least some $\beta$-type retinal ganglion cells appear to make a transient "inappropriate" connection to the superior colliculus (Ramoa ct al., 1989), while $\alpha$ - and $\gamma$-typc ganglion cells retain this connection into adulthood (Wassle and Illing, 1980; Leventhal 

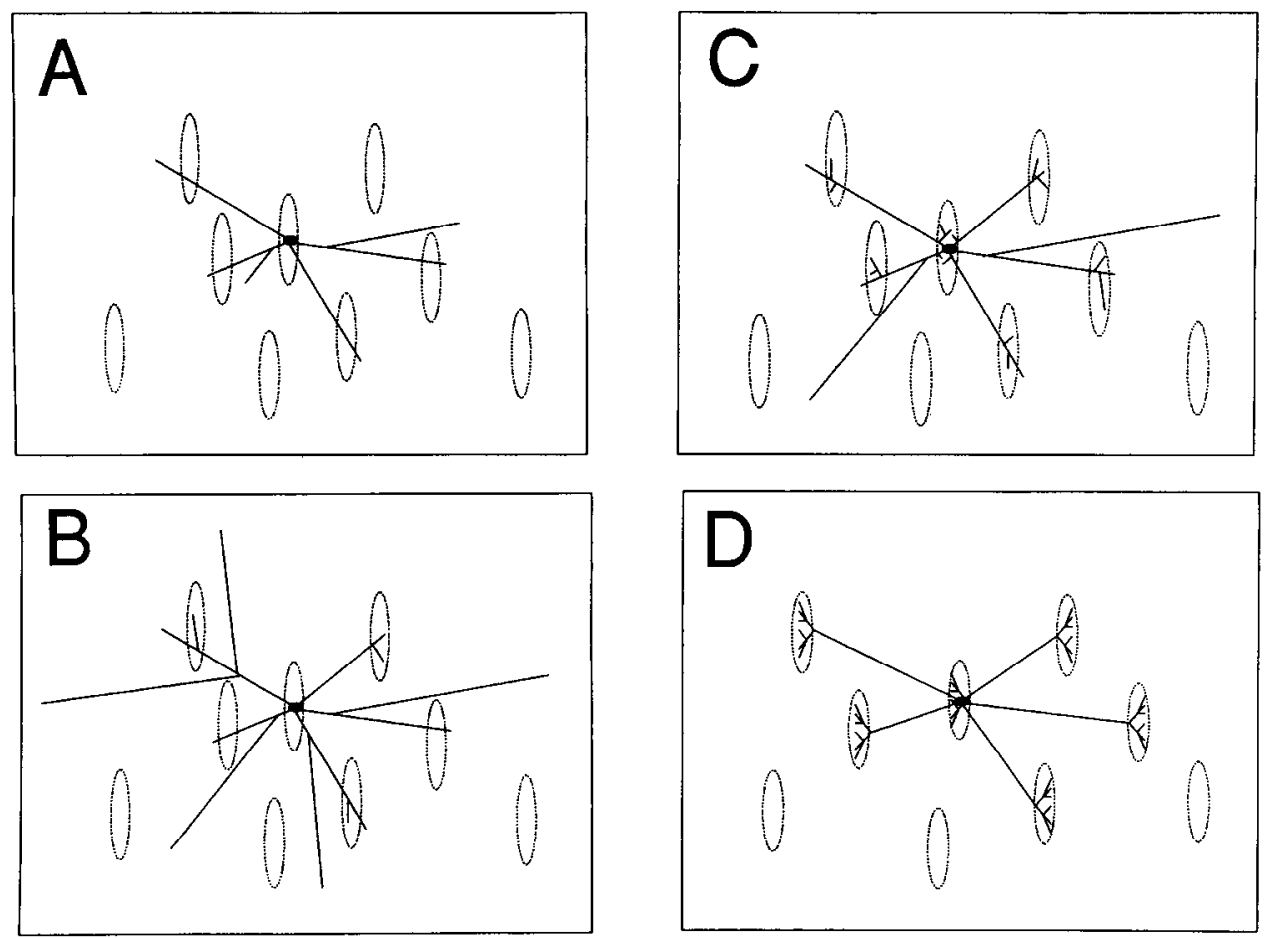

Figure 15. Summary of the developmental changes in the axonal arborization of an idealized superficial pyramidal cell in striate cortex. The dark oval at the center of each figure represents the cell body, lines represent axonal processes, and dotted oval outlines represent regions where the orientation selectivity is or will be the same as for the neuron shown. $A$, Idealized P8-10 horizontal axonal arbor. Horizontal collaterals initially extend from near the cell body and seldom form branches more distally. While outgrowth during the first postnatal week is not biased toward regions of same presumptive orientation, retrograde labeling at P8 suggests that there is already some bias early in the second week. $B$, Idealized P14-21 horizontal axonal arbor. During the third postnatal week, the number and length of horizontal collaterals increase and there is occasional secondary branching distal to the cell body. The crudely clustered pattern of intrinsic retrograde label at these ages suggests that the secondary branches may be within appropriate (same orientation) target regions. The number of horizontal axon collaterals depicted here is more typical of cells observed early in the second week (Fig. 11); the number in the third week is about 2- to 3-fold greater (Fig. 12). C, Idealized P28-35 horizontal axonal arbor. The axonal arbors observed at this age appeared more clustered due to the selective elimination of inappropriately projecting collatcrals and the elaboration of immature clustered secondary branches. $D$, Idealized P42-adult horizontal axonal arbor. Any remaining inappropriate connections have been eliminated and axon collaterals have branched extensively within appropriate target regions.

et al., 1985). During the development of the retinogeniculate projection, individual axonal arbors are initially exuberant in their extent, but are later pruned such that they occupy only the geniculate lamina corresponding to their eye of origin (Sretavan and Shatz, 1986).

We have described the timing and mechanisms underlying the maturation of clustered horizontal connections in cat striate cortex and have found that the development of intrinsic connections within a cortical area also includes a period of exuberant connectivity. This description was based on both neuronal pathway tracing, which elucidated the patterns of connections of populations of cells to and from injection sites within area 17, and in vitro intracellular staining which revealed developmental changes in the horizontal axonal arbors of individual cells.

\section{Timing of cluster formation}

We observed very crude clustering of retrogradely labeled cells as early as the start of the second postnatal week, in agreement with previous studies of the development of clustered intrinsic horizontal connections in the cat. Price (1986) reported that injections of WGA-HRP in area 18 resulted in clear clustering of retrogradely labeled cells in that same area at P20 and "some evidence for an uneven distribution" at P10. In area 17, Luhmann et al. (1986) also using WGA-HRP, reported clustering at P10.
Luhmann et al. did not report results from animals younger than P10, while Price reported that clustering was not apparent in area 18 at $\mathrm{P} 4$.

The use of fluorescent latex microspheres as a retrograde label had several advantages over the use of WGA-HRP, the most important being that injections were confined to a small area, typically $100-400 \mu \mathrm{m}$ in diameter. Since clustered connections interconnect regions of similar orientation preference in cat striate cortex (Gilbert and Wiesel, 1989) and orientation columns are spaced with a periodicity of only about $1 \mathrm{~mm}$, tracer injections that are not substantially smaller than $1 \mathrm{~mm}$ result in a cruder pattern of retrograde label (data not shown). Because WGAHRP, like virtually all retrograde tracers, diffuses from an injection site, it is difficult to make pressure injections much smaller than about $1 \mathrm{~mm}$ in diameter. This is especially true for younger animals, in which substances diffuse even further than in the adult. Thus, using fluorescent latex microspheres, we were able to observe developmental changes in the pattern of horizontal intrinsic connections that might not have been apparent with larger injections. These changes included (1) the transition from an unclustered distribution of retrogradely labeled cells following injections during the first postnatal week to the crudely clustered distribution observed following injection at P8 and (2) the transition from crude clustering early in development (P12- 
14) to refined clusters in which few cells between clusters project to the injection site after 6 weeks postnatally.

\section{Mechanisms of cluster formation and refinement}

We tested whether selective cell death or process elimination contribute to the development of intrinsic horizontal connections. The appearance of a crudely clustered pattern of retrogradely labeled cells from an earlier unclustered pattern could result from either progressive or regressive phenomena. Since we were able to rule out cell death as the mechanism responsible for this transition, the likely remaining possibilities were selective collateral outgrowth and selective elimination of inappropriately projecting axons. Although the early clustered pattern arises from a diffuse unclustered pattern, it is possible that regressive events do not contribute to the change; the density of labeled cells at P4-6 may correspond to the density between clusters at P12-14 (cf. Figs. 4, $A, B$ and 5, $A, C$ ). Thus, the initial emergence of crude clusters could be attributed to an increased density at clusters arising from directed process outgrowth. In view of evidence that selective process elimination contributes to the later refinement of clustering, process elimination also remains a likely contributor to early clustering. Thus, while we can rule out cell death as the mechanism responsible for this transition, both selective process elimination and directed axon outgrowth are likely alternatives, perhaps making simultaneous contributions.

As was the case for the formation of crude clusters early in development, our results indicate that selective cell death was not responsible for the subsequent refinement of those clusters. Two separate lines of evidence point toward selective process elimination as the mechanism responsible for refinement of clusters. First, there was an approximately $50 \%$ reduction in the number of axons extending from LY-filled neurons between P23 and P30-a period during which results from microsphere injections indicated that cluster refinement was occurring. One potential shortcoming of this finding in arguing for process elimination is that the $350-\mu \mathrm{m}$-thick slices used in this study are not likely to have contained the cntire axonal arbor of any cell. However, the likelihood of exclusion of axonal branches is probably similar in P23 and P30 slices. Also, we counted the number of axon branches extending from near the cell body; this is the location where axons are least likely to leave the plane of the slice. Thus, we feel that a difference of the magnitude we observed (reduction from about 30 to 15 axons per cell) is unlikely to have occurred by this type of artifact.

Observation of a reduction in axonal processes does not however necessitate that specific axonal branches were selectively removed. However, when 2 tracers (red and green microspheres) were injected at the same location at 2 different ages (P15 and P29), the resultant double-labeled cells were confined to the centers of the crude clusters resulting from the P15 injection and were arranged in the typical adultlike refined pattern. There was a specific reduction in the number of cells making inappropriate projections to the injection site that was not due to cell death. Together the results from the LY-fills and microsphere injections strongly indicate a selective removal of axons projecting to incorrect targets; this removal resulted in the refinement of horizontal axonal arbors such that the degree of specificity of connections more closely matched that of the adult.

Another study of the development of intrinsic horizontal connections in area 17 (Luhmann et al., 1986) reported a marked decrease in the tangential extent of WGA-HRP transport be- tween the fourth and eighth postnatal weeks, and further noted that microsphere injection in one kitten resulted in retrogradely labeled cells up to $10.5 \mathrm{~mm}$ from the injection site. These results were interpreted to suggest that the length of tangential axons was dramatically reduced during development. We find no evidence for such a change with any of the 3 methods we usedDiI, microspheres, or intracellular injections. The most extensive labeling we observed in any microsphere-injected animal was $4.2 \mathrm{~mm}$ from the injection site. This value was obtained for both a P19 and a P37 injection. Gilbert and Wiesel (1989) reported a pattern with a $4.5 \mathrm{~mm}$ extent in an adult cat. We have observed more extensive label only in cases which were excluded from our analysis because the microsphere injections involved the white manner. Thus, while we cannot rule out a modest change in the length of horizontal axons that might have been obscured by interanimal variability, it is clear that the lateral extent of intrinsic retrograde label in the adult can be at least as great as that observed in any younger animals.

\section{Relationships between cluster development and the emergence of orientation selectivity}

Clustered intrinsic connections in area 17 interconnect regions of similar orientation selectivity in the adult cat (Gilbert and Wiesel, 1989). Our results strongly suggest that the crude clusters observed between P8 and P14 already interconnect regions where neurons have, or are destined to have, similar orientation preferences. When red and then green microspheres were sequentially injected at the same location (P15 then P29), the resultant clusters were overlapping (a similar result was obtained with injections at P8 and P14, data not shown). Thus, the positions of cells making clustered connections to a single site does not shift during this time in an animal with normal visual experience. This result suggests that the positions of presumptive orientation columns and their relations to one another are already present at a time when only a small minority of neurons are visually responsive, and of those, only a fraction responds selectively to oriented visual stimuli (Albus and Wolf, 1984). The result further suggests that those cells that arc oricntation sclective are likely to already be arranged in a columnar order, as first noted by Hubel and Wiesel (1963; see also Blakemore and Van Sluyters, 1975), an issue which has thus far been difficult to address straightforwardly (see Fregnac and Imbert, 1984, for review).

\section{Comparisons with other systems}

There are several similarities between the development of intrinsic horizontal connections in area 17 and the area 17 to area 18 corticocortical connection, both of which interconnect regions of similar orientation preference in the adult (Gilbert and Wiesel, 1989). These similarities suggest that the 2 circuits might develop in parallel by a common mechanism. Clustering is first apparent for both circuits at about the same age (P8-10), and appearance of clusters apparently depends on selective process elimination but not selective cell death (Price and Blakemore, $1985 \mathrm{a}, \mathrm{b})$. While the 17-to-18 projection might also be refined at the same time as intrinsic clusters within area 17 , it is not possible to make this determination based on the results presently available; the results of Price and Blakemore are based on relatively large tracer injections observed in coronal sections, which might not elucidate subtle changes in the pattern of connections. Similarly, a period of refinement of clustered intrinsic connections has not yet been demonstrated in area 18 since the 
only developmental study of those connections was based on WGA-HRP injections (Price, 1986).

In mammalian systems where the development of axonal arbors has been studied, there are noteworthy similarities in the sequence of events underlying their maturation. The most striking similarities are found between the development of retinogeniculate connections (Sretavan and Shatz, 1986) and of intrinsic horizontal connections in area 17 (this study). Both circuits undergo 3 similar phases of development: (1) the initial axonal arbor covers both appropriate and inappropriate target regions but is relatively sparse; (2) connections to inappropriate regions are selectively eliminated; and (3) after the basic axonal framework occupies only appropriate regions, axons then branch extensively and specifically within appropriate regions to attain their final adultlike morphology. A similar strategy is also employed in the formation and refinement of topographic connections from retina to superior colliculus (Schneider et al., 1987) and from the geniculate to visual cortex in the hamster (Naegele et al., 1988). These appear to be prudent strategies in that neurons do not invest large amounts of materials and energy elaborating extensive terminal arbors, only to eliminate them later; the suitability of prospective territories for permanent innervation is sampled by simple, relatively unbranched axons. We feel it is likely that the sequence of events will prove to be similar in other systems where inappropriate connections are eliminated. For example the restriction of geniculocortical connections to eye-specific columns may occur while the axonal arbors are still relatively sparse (but see Le Vay and Stryker, 1979).

\section{Possible roles of activity}

There is a noteworthy correspondence between the timing of the maturation or intrinsic horizontal connections and both the onset of spontaneous cortical activity and the appearance of orientation selectivity. Huttenlocher (1967) reported that spontaneous cortical activity could not be recorded in cats younger than P4 and was infrequent at P4-7. Levels of spontaneous activity increased in older animals, but units with rapid repetitive activity were not observed until about 3 weeks postnatally. Thus, the initial clustering of intrinsic horizontal connections at P8 may be related to the onset of spontaneous activity and the transition from outgrowth to retraction of long horizontal axons after the third postnatal week might be due to increasing activity levels.

Albus and Wolf (1984) report several relevant findings regarding the development of visual responsiveness and orientation selectivity of visual cortical neurons from specific layers in neonatal kittens. They report a normal number of visually responsive neurons in layers 4 and 6 of area 17 as early as P69 , but an extremely low number at the same ages in layers $2 / 3$ and 5 . About $70 \%$ of the visually responsive cells already show some bias in their responses to oriented stimuli, although the proportion of "selective" cells is only about $10 \%$. The percentage of orientation-selective cells increases rapidly shortly after eye opening (about P8) but in layers $2 / 3$ and 5 the appearance of large numbers of selective cells is delayed until the third postnatal week since few cells in these layers are visually responsive before that time.

There are some interesting parallels between these events and the development of clustered intrinsic connections in layers $2 / 3$ and 5. We find that the age at which clustering is first apparent (P8) is the same in both supra- and infragranular layers. The timing of the appearance of visual responsiveness and orien- tation selectivity is also similar for these layers. Since at least sparse connections from layer $2 / 3$ to 5 are known to be present as early as P5 (Katz and Wiesel, 1987) these results suggest that the onset of clustering as well as the appearance of visual responsiveness in these layers might be triggered by the formation of connections from cells in layer 4 to those in layer $2 / 3$. Our preliminary results suggest that such connections begin to appear early in the second postnatal week. Perhaps as the number of layer 4 to $2 / 3$ connections grows, resulting in more visually responsive and orientation-selective neurons in supra- and infragranular layers, these neurons are able take advantage of the activity cues to direct the formation of long-distance intrinsic connections toward more appropriate targets and/or to selectively eliminate inappropriate connections.

The available data from physiological (Albus and Wolf, 1984) and our anatomical studies suggest the following scenario for the development of clustered intrinsic connections and for the relationship between the timing of the development of this intrinsic circuitry relative to that of other intrinsic circuits in striate cortex. Our hypothesis is based on the assumption that pyramidal neurons making long-distance horizontal connections use activity cues to identify appropriate target cells having similar orientation selectivity. This identity could be established based on the level of correlation between pre- and postsynaptic activity; physiological studies in adult cat striate cortex have identified correlated activity between pairs of neurons separated by several millimeters and having non-overlapping receptive fields so long as they were in columns of similar orientation preference (T'so et al., 1986).

We suggest that orientation bias and a "columnar" arrangement are already established in layer 4 prior to the elaboration of connections from layer 4 to layer $2 / 3$, probably during the first postnatal week when pyramidal cells begin to extend long horizontal axons but show no sign of clustering. The absence of activity cues within layer $2 / 3$ that could convey the identity of orientation domains does not allow the developing horizontal axons to distinguish between correct and incorrect targets. We suspect that axons of layer 4 cells begin to invade the superficial layers during the second postnatal week, shortly after natural eye opening, leading to increased visual activity in supra- and infragranular layers. Since the responses of the cells in the supraand infragranular layers already have orientation biases, these cues could be used to reinforce alrcady cxisting conncctions, and/or direct the formation of new connections, between cells in columns of similar orientation. This could lead to the crude clustering of connections observed during the second and third postnatal weeks. The persistence of visually unresponsive neurons and broad orientation tuning (Albus and Wolf, 1984) would allow the formation and maintenance of some connections with inappropriate synaptic partners. The subsequent elimination of inappropriately projecting collaterals observed after the third postnatal week corresponds to the time of appearance of adultlike levels of orientation selectivity and continued increases in visual responsiveness in layers $2 / 3$ and 5 .

Since the transition from orientation-biased to orientationselective cells occurs most notably in layers 4 and 6 , with orientation selectivity being apparent in layers $2 / 3$ and 5 as early as the cells are visually responsive (Albus and Wolf, 1984), it follows that the improvement in activity cues available to neurons making clustered connections is more likely related to increased visual responsiveness (perhaps related to the strength of the 4 to $2 / 3$ connections) than improved orientation selec- 
tivity; improvements in selectivity may occur at an earlier processing stage and be relayed to the more superficial laminae by the layer 4 to $2 / 3$ connection (but see Malpeli, 1983).

In this model, experimental manipulations that alter orientation selectivity or visual responsiveness of cortical neurons should have predictable influences on the development of clustered intrinsic connections. One well-studied manipulation is binocular deprivation. Although neurons in binocularly deprived cats remain organized in columns, they tend to remain broadly tuned for orientation and the proportion of cells that are visually responsive fails to increase normally (Hubel and Wiesel, 1963; Blakemore and Van Sluyters, 1975). Thus, binocular deprivation should not prevent the appearance of crude clustering of intrinsic horizontal connections during the second postnatal week because the response properties and activity levels of the neurons involved should be adequate to allow this level of crude specificity. In fact, clustering of horizontal connections in binocularly deprived animals has been observed (Luhmann et al., 1986; Price, 1986). However, binocular deprivation should prevent the refinement of clusters. This might occur by a failure to eliminate exuberant axon collaterals, or by a normal degree of elimination but with little or no specificity due to the lack of normal activity cues.

\section{References}

Albus, K., and W. Wolf (1984) Early post-natal development of neuronal function in the kitten's visual cortex: A laminar analysis. J. Physiol. (Lond.) 348: 153-185.

Blakemore, C., and R. C. Van Sluyters (1975) Innate and environmental factors in the development of the kitten's visual cortex. J. Physiol. (Lond.) 248: 663-716.

Fregnac, Y., and M. Imbert (1984) Development of neuronal selectivity in primary visual cortex of the cat. Physiol. Rev. 64: 325-434.

Geisert, E. E. (1980) Cortical projections of the lateral geniculate nucleus in the cat. J. Comp. Neurol. 190: 793-812.

Gilbert, C. D., and T. N. Wiesel (1979) Morphology and intracortical projections of functionally characterised neurones in the cat visual cortex. Nature 280: 120-125.

Gilbert, C. D., and T. N. Wiesel (1983) Clustered intrinsic connections in cat visual cortex. J. Neurosci. 3: 1116-1133.

Gilbert, C. D., and T. N. Wiesel (1989) Columnar specificity of intrinsic horizontal and corticocortical connections in cat visual cortex. J. Neurosci. 9: 2432-2442.

Godement, P., J. Vanselow, S. Thanos, and F. Bonhoeffer (1987) A study in developing visual systems with a new method of staining neurones and their processes in fixed tissue. Development 101:697713.

Henderson, Z. (1982) An anatomical investigation of projections from lateral geniculate nucleus to visual cortical areas 17 and 18 in newborn kitten. Exp. Brain Res. 46: 177-185.

Hollander, H., and H. Vanegas (1977) The projection from the lateral geniculate nucleus onto the visual cortex of the cat. A quantitative study with horseradish-peroxidase. J. Comp. Neurol. 173: 519-536.

Hubel, D. H., and T. N. Wiesel (1963) Receptive fields of cells in striate cortex of very young, visually inexperienced kittens. J. Neurophysiol. 26: 994-1002.

Huttenlocher, P. R. (1967) Development of cortical neuronal activity in the neonatal cat. Exp. Neurol. 17: 247-262.

Innocenti, G. M., and R. Caminiti (1980) Postnatal shaping of callosal connections from sensory areas. Exp. Brain Res. 38: 381-394.

Kalil, R. (1978) Development of the dorsal lateral geniculate nucleus in the cat. J. Comp. Neurol. 182: 265-292.

Katz, L. C. (1987) Local circuitry of identified projection neurons in cat visual cortex brain slices. J. Neurosci. 7: 1223-1249.

Katz, L. C., and D. M. Iarovici (1989) Green fluorescent latex microspheres: A new retrograde tracer. Neuroscience (in press).

Katz, L. C., and T. N. Wiesel (1987) Postnatal development of intrinsic axonal arbors of pyramidal neurons in cat striate cortex. Soc. Neurosci. Abstr. 13: 1025.
Katz, L. C., A. Burkhalter, and W. J. Dreyer (1984) Fluorescent latex microspheres as a retrograde neuronal marker for in vivo and in vitro studies of visual cortex. Nature 310: 498-500.

Katz, L. C., C. D. Gilbert, and T. N. Wiesel (1989) Local circuits and ocular dominance columns in monkey striate cortex. J. Neurosci. 9: 1389-1399.

Le Vay, S., and M. P. Stryker (1979) The development of ocular dominance columns in the cat. Soc. Neurosci. Symp. 4: 83-98.

Leventhal, A. G., R. W. Rodieck, and B. Dreher (1985) Central projections of cat retinal ganglion cells. J. Comp. Neurol. 237: 216-226.

Livingstone, M. S., and D. H. Hubel (1984) Specificity of intrinsic connections in primate primary visual cortex. J. Neurosci. 4: 28302835.

Luhmann, H. J., L. Martinez Millan, and W. Singer (1986) Development of horizontal intrinsic connections in cat striate cortex. Exp. Brain Res. 63: 443-448.

Luskin, M. B., and C. J. Shatz (1985) Neurogenesis of the cat's primary visual cortex. J. Comp. Neurol. 242: 611-631.

Malpeli, J. G. (1983) Activity of cells in area 17 of the cat in absence of input from layer A of lateral geniculate nucleus. J. Neurophysiol. 49: 595-610.

Martin, K. A. C., and D. Whitteridge (1984) Form, function and intracortical projections of spiny neurones in the striate visual cortex of the cat. J. Physiol. (Lond.) 353: 463-504.

Naegele, J. R., S. Jhaveri, and G. E. Schneider (1988) Sharpening of topographical projections and maturation of geniculocortical axon arbors in the hamster. J. Comp. Neurol. 277: 593-607.

O'Leary, D. D. M., and T. Terashima (1988) Cortical axons branch to multiple subcortical targets by interstitial axon budding: Implications for target recognition and "waiting periods." Neuron 4: $901-$ 910.

O'Leary, D. D. M., B. B. Stanfield, and W. M. Cowan (1981) Evidence that the early postnatal restriction of the cells of origin of the callosal projection is due to the elimination of axonal collaterals rather than to the death of neurons. Dev. Brain Res. 1:607-617.

Otsuka, R., and H. Hassier (1962) Uber aufbau und gliederung der corticalen sehsphare bei der katze. Arch. Psych. Nevenkr. 203: 212 234.

Price, D. J. (1986) The postnatal development of clustered intrinsic connections in area 18 of the visual cortex in kittens. Dev. Brain Res. 24: $31-38$.

Price, D. J., and C. Blakemore (1985a) Regressive events in the postnatal development of association projections in the visual cortex. Naturc 316: 721-724.

Price, D. J., and C. Blakemore (1985b) The postnatal development of the association projection from visual cortical area 17 to area 18 in the cat. J. Neurosci. 5: 2443-2452.

Purves, D., and J. W. Lichtman (1985) Principles of Neural Development, Chaps. 6, 12, Sinauer, Sunderland, MA.

Ramoa, A. S., G. Campbell, and C. J. Shatz (1989) Retinal ganglion $\beta$-cells project transiently to the superior colliculus during development. Proc. Natl. Acad. Sci. USA 86: 2061-2065.

Rockland, K. S. (1985) Anatomical organization of primary visual cortex (area 17) in the ferret. J. Comp. Neurol. 241: 225-236.

Rockland, K. S., and J. S. Lund (1983) Intrinsic laminar lattice connections in primate visual cortex. J. Comp. Neurol. 206: 303-318.

Sanderson, K. J. (1971) The projection of the visual field to the lateral geniculate and medial interlaminar nuclei in the cat. J. Comp. Neurol. 143: 101-118.

Schneider, G. E., S. Jhaveri, and W. F. Davis (1987) On the development of neuronal arbors. In Developmental Neurobiology of Mammals, C. Chagas and R. Linden, eds., pp. 31-64, Pontifical Academy of Sciences, Vatican City, Italy.

Shatz, C. J., and M. B. Luskin (1986) The relationship between the geniculocortical afferents and their cortical target cells during development of the cat's primary visual cortex. J. Neurosci. 6:3655-3668.

Sretavan, D. W., and C. J. Shatz (1986) Prenatal development of retinal ganglion cell axons: Segregation into eye-specific layers within the cat's lateral geniculate nucleus. J. Neurosci. 6: 234-251.

Stanfield, B. B., and D. D. M. O'Leary (1985) The transient corticospinal projection from the occipital cortex during the postnatal development of the rat. J. Comp. Neurol. 238: 236-248.

Tootell, R. B. H., and M. S. Silverman (1985) Two methods for flatmounting cortical tissue. J. Neurosci. Methods 15: 177-190.

T'so, D. Y., C. D. Gilbert, and T. N. Wiesel (1986) Relationships 
between horizontal interactions and functional architecture in cat striate cortex as revealed by cross-correlation analysis. J. Neurosci. 6: $1160-1170$.
Wassle, H., and R.-B. Illing (1980) The retinal projection to the superior colliculus in the cat: A quantitative study with HRP. J. Comp. Neurol. 190: 333-356. 